\title{
Perceiving geographical slant
}

\author{
DENNIS R. PROFFITT, MUKUL BHALLA, RICH GOSSWEILER, and JONATHAN MIDGETT \\ University of Virginia, Charlottesville, Virginia
}

\begin{abstract}
People judged the inclination of hills viewed either out-of-doors or in a computer-simulated virtual environment. Angle judgments were obtained by having people (1) provide verbal estimates, (2) adjust a representation of the hill's cross-section, and (3) adjust a tilt board with their unseen hand. Geographical slant was greatly overestimated according to the first two measures, but not the third. Apparent slant judgments conformed to ratio scales, thereby enhancing sensitivity to the small inclines that must actually be traversed in everyday experience. It is proposed that the perceived exaggeration of geographical slant preserves the relationship between distal inclination and people's behavioral potential. Hills are harder to traverse as people become tired; hence, apparent slant increased with fatigue. Visually guided actions must be accommodated to the actual distal properties of the environment; consequently, the tilt board adjustments did not reflect apparent slant overestimations, nor were they influenced by fatigue. Consistent with the fact that steep hills are more difficult to descend than to ascend, these hills appeared steeper when viewed from the top.
\end{abstract}

By east coast standards, Virginia is a mountainous state, and many of its roads appear quite steep, especially to midwestern visitors. Yet by law, roads in the state can be inclined no more than $9^{\circ}$ from the horizontal, and $9^{\circ}$ is a much smaller angle than the inclination that most people estimate these steep roads to have. This is an example of a pervasive phenomenon: Hills appear to be steeper than they actually are. The first purpose of this paper is to provide a normative description of this overestimation in geographical slant perception.

As we will show, a $5^{\circ}$ hill is typically judged to be almost $20^{\circ}$ in slant; however, when walking up a $5^{\circ}$ hill, we do not raise our feet to accommodate a $20^{\circ}$ incline and thereby stumble as we begin the ascent. The visual guidance of locomotion shows no evidence of slant misperception. The second purpose of this paper is to show that a motoric index of geographical slant shows little evidence of the overestimations manifest in visual awareness. The paper's third purpose may be introduced with an anecdote.

Not long ago, I (Proffitt) was riding in a 1-day, 100-mile, bicycle tour, with the finish-line only a couple of miles ahead. The tour had traversed a number of small mountains in a circuit that began and ended at a site in the rolling hills of the Virginia piedmont. The final hill before the finish seemed incredibly steep, and as I passed another rider I commented on how organizers of these affairs always seemed to arrange for the steepest hills to be located just

This research was supported by NIMH Grant MH5240-01 and NASA Grant NCC2-5074 to the first author. The authors are very grateful for the assistance provided by Marco Bertamini, Bennett Bertenthal, Sarah Creem, Jim Durbin, Frank Durgin, Jane Joseph, and Shahwar Qureshi. The development of our ideas benefitted greatly from numerous conversations with Jack Loomis. Nicola Bruno, William Ittelson, and Johan Wagemans provided valuable criticism on an earlier version of this paper. Correspondence concerning this article should be addressed to D. R. Proffitt, Department of Psychology, Gilmer Hall, University of Virginia, Charlottesville, VA 22903-2477 (e-mail: drp@virginia.edu). before the finish. The other rider muttered an oath as she bemoaned what a cruel joke it was to make us climb this hill so late in the ride. (It would have been an even crueler joke to have informed her that the incline of this hill was only about $7^{\circ}$.) Now the hill in question was relatively steep, but it was far less so than many that we had previously encountered during this day of cycling. The third purpose of this paper is to show that the apparent steepness of this hill was due, in part, to our state of physical fatigue. Hills do, indeed, look steeper when we are tired than when we are not.

We interpret these findings to imply that our conscious perceptions of geographical slant are highly exaggerated. Moreover, we argue that these perceptions are distorted in a manner that is well suited for the purposes of guiding locomotion in the environment. For most of us who live outside of San Francisco, the effective range of slopes that we walk up and down is between $0^{\circ}$ and $10^{\circ}$. A $10^{\circ}$ hill is quite difficult to climb for any distance, and it looks very steep to us. A $30^{\circ}$ hill is about the limit of what we can walk up, and it is too steep to walk down without risk of slipping and falling. The top of a $30^{\circ}$ hill is a dangerous place. We will show that, unlike smaller inclines, such hills look steeper from the top than from the bottom. We will argue that geographical slant perception relates the actual physical slant of inclines to our behavioral potential. For this reason, steep hills look steeper from the top and all hills look steeper when we are fatigued. In this regard, we will suggest that we perceive the affordances of slopes as opposed to their purely distal characteristics. Finally, we will suggest that the reason that people can locomote skillfully in the context of gross overestimations of slant is related to the separation of visual pathways that support conscious perception versus motoric action.

\section{Geographical Slant}

Geographical slant refers to the inclination of surfaces relative to the environmentally specified horizontal. There 
are three different ways in which surface slant can be defined, depending on which of three reference frames is selected. Relative slant specifies the orientation of one surface with respect to the reference frame provided by another. Optical slant is specified in relation to the line of sight from the point of observation to the surface in question. Finally, geographical slant is specified in relation to a fixed environmental frame of reference, typically the horizontal ground plane (Gibson \& Cornsweet, 1952). As examples of these three slant representations, imagine a book being held during normal reading and consider the slant of the page that is being read. The relative slant of this surface with respect to the facing page would be about $170^{\circ}$, its optical slant would be approximately $0^{\circ}$, and its geographical slant would be around $45^{\circ}$. In this paper, we are concerned with geographical slant--slant specified in relation to the horizontal plane of the ground.

Geographical slant is independent of viewpoint. Its magnitude is specified in relation to the horizontal, as can be seen in Figure 1. The intersection of a surface with a horizontal plane defines a line. From any point on this line, perpendicular lines can be drawn along both the sur- face and the horizontal plane. Slant is defined by the smaller of the two supplementary angles formed by the intersection of the latter two lines. With respect to a Cartesian representation in which the $x$ - and $z$-axes define the ground plane and the $y$-axis specifies the vertical direction, a given slant angle has a vertical direction, but its orientation with respect to the $x$ - and $z$-axes is unspecified.

When an observer's viewpoint is taken into account, the orientation of an incline comprises $x$ - and $z$-axis components. If the $z$-axis is assigned to the direction of the line of sight, pitch is defined as the surface's rotation away from horizontal around the $x$-axis, and roll is its rotation around the $z$-axis. When one faces a hill, pitch is equivalent to slant, whereas when one looks at a side view of an incline, roll is equivalent to slant.

In the present studies, and in all others conducted to date, the perception of slant has been investigated in situations in which people are directly facing the incline. This is shown in Figures la- $1 \mathrm{~b}$. In these contexts, slant is equivalent to the pitch angle that the surface makes with respect to the ground.

(a)

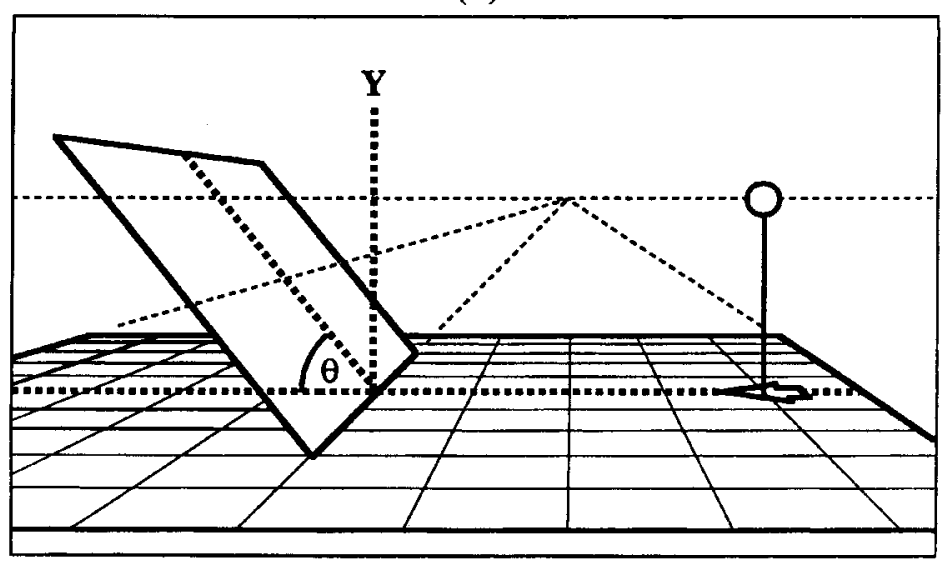

(b)

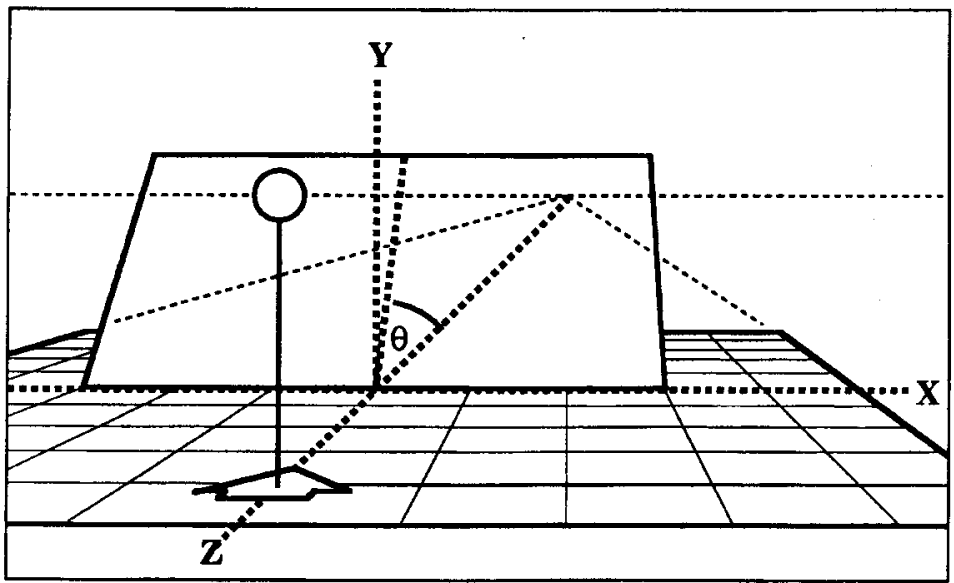

Figure 1. Two views of a surface intersecting the horizontal ground plane. An observer is depicted as an eye (sphere) on a pole with an arrow at the feet indicating direction of gaze. Slant is equal to $\theta$. 


\section{Perceiving Geographical Slant}

In general, studies of slant perception have been of two sorts: those pertaining to optical slant and those dealing with geographical slant. The former are relevant here, since in those studies the observer's line of sight has typically been horizontal, so that optical and geographical slant were the same.

In studies of optical slant, researchers have been concerned primarily with the stimulus variables that influence its perception. In such studies, viewing conditions have been reduced, and subjects have been asked to indicate the pitch of a display relative to their line of sight. The displays have been presented on computer or projection screens, or subjects have had to view surfaces through the aperture in a reduction screen. A variety of stimulus variables have been manipulated, with texture being studied most frequently. Investigators have assessed the influence of texture gradients (Epstein, 1981; Eriksson, 1964; Flock, 1964; Gibson, 1950; Gibson \& Cornsweet, 1952; Kraft \& Winnick, 1967); texture regularity (Gibson, 1950); and size, compression, and spacing of texture elements (Flock, 1964; Freeman, 1966a; Gillam, 1970; Phillips, 1970). Other variables studied have included linear perspective (Clark, Smith, \& Rabe, 1956a; Epstein \& Mountford, 1963; Smith, 1966), projective size (Flock, 1964; Flock, Graves, Tennet, \& Stephenson, 1967; Freeman, 1966b; Smith, 1967), and motion parallax and binocular disparity (Braunstein, 1968; Clark, Smith, \& Rabe, 1956b; Willey \& Gyr, 1969).

A common finding in all of these studies has been that surfaces appear to lie closer to the frontoparallel plane than the perspective projection indicates. Thus, subjects have systematically underestimated the pitch in relation to the picture plane. (Note that underestimation from the picture plane is equivalent to overestimation from the ground plane.) Generally, it has been thought that these underestimations are due to a tendency of judgments to conform to the pitch of the projection surface or reduction screen (Epstein \& Park, 1963). Why this underestimation occurs remains an unresolved issue; however, the source of error seems to lie in perceptual processes as opposed to the availability of reliable information (Perrone \& Wenderoth, 1991).

The results obtained in these studies of optical slant perception are similar to those found for the perception of geographical slant: Perceived pitch is invariably overestimated in relation to the horizontal ground plane (underestimated relative to the vertical picture plane). Nevertheless, one must be cautious in generalizing from what has been found in the studies of optical slant to everyday geographical pitch perception. This is because in any given optical slant study, observers have been presented with quite limited information, and either the projection surface has been visible or viewing has occurred through an aperture. These studies have focused on how selected information influences optical slant perception, not on the phenomenology of everyday geographical slant perception.

Despite the apparent ecological importance of geographical slant-it is invariant over points of view, whereas optical slant is not-few studies on geographical pitch perception are to be found in the literature. ${ }^{1}$ Kammann (1967), who appears to have been the first and only researcher to systematically investigate the magnitude of slant overestimation for real hills, found that, when viewed from the top, a $34^{\circ}$ hill was estimated to have a $48^{\circ}$ pitch by males and a $55^{\circ}$ pitch by females. Ross (1974) provided a number of anecdotal accounts of slant overestimation for real hills viewed from both the top and the bottom; her description of the magnitude of overestimations are in line with Kammann's findings.

\section{Visually Guided Actions Related to Geographical Slant}

Although people overestimate geographical slant, they are not especially accident prone when walking up and down hills. The inefficacy of conscious slant misperceptions with respect to visually guided actions has been nicely demonstrated in a set of studies conducted by KinsellaShaw, Shaw, and Turvey (1992). They showed that people are able to accurately judge the maximum inclination that they can walk up, and more importantly for our purposes, that people are also good at matching the pitch of a distal surface with that of a haptically perceived surface.

Kinsella-Shaw et al. (1992) conducted two experiments. In the first, subjects adjusted a large frontal platform to the maximum pitch that they could comfortably walk up. They were then tested for the maximum pitch that they could actually traverse by being asked to walk up an incline that was set to the pitch that they had previously given as the maximum possible. Subjects' initial perceptual judgments were found to be good predictors of the maximum incline that they could climb. In the second experiment, subjects again adjusted the inclination of the visible platform, but this time to match the pitch of a small ramp on which their right feet rested. This ramp was inclined between $0^{\circ}$ and $50^{\circ}$ and was occluded from the subjects' view. Subjects were quite accurate at matching the visible platform to the haptically presented surface. They were also good at judging whether the inclination thus set would be conducive to normal walking or not.

Kinsella-Shaw et al.'s (1992) study indicates that visually guided actions show little or no evidence of the slant overestimations that are evoked when people provide verbal estimates of pitch. In the following experiments, we sought to confirm this relationship by investigating the nature of geographical slant perception.

\section{Overview to the Experiments}

Five experiments were conducted. In the first, we obtained geographical pitch judgments from a large number of people on nine different hills viewed from the bottom. Three measures were employed: People gave verbal judgments; they performed a visual matching task; and they adjusted a tilting board with their unseen hand, thereby providing a haptic measure. Large overestimations of pitch were obtained for the first two measures but not for the third. The second experiment replicated the first, except that observers viewed the hills from the top. In comparing the results of this study with those from the first, it was 
found that steep hills were overestimated more from the top than from the bottom. Again, haptic judgments were far more accurate. Experiments 3 and 4 replicated the previous two studies in a computer-simulated virtual environment. A wider range of pitch angles was investigated, and the results coincided closely with those of the experiments conducted out-of-doors on real hills. Finally, in Experiment 5 we assessed geographical pitch perception before and after fatiguing exercise. We found that, after exercise, subjects judged hills to be steeper on the verbal and visual measures but not on the haptic one.

\section{EXPERIMENT 1 Real Hills Viewed From the Base}

The primary purpose of this experiment was to collect normative data on everyday geographical pitch perception. Previously, only Kammann's (1967) assessment of one hill and Ross's (1974) anecdotal accounts had provided data on the magnitude of geographical slant overestimation in natural viewing contexts. In Experiment 1, subjects faced hills, standing at their base, and provided pitch angle estimates by using three different measures: verbal, visual, and haptic. The verbal measure was an oral report of what the subject thought the pitch of the hill was in degrees. The visual measure was obtained by having subjects adjust a disk that represented the cross-section of the hill. The haptic measure used a tilt board which could be adjusted with one's unseen hand, either upward or downward, to match it to the pitch angle of the hill. In addition, we assessed the internal consistency of these three measures. For this purpose, subjects were asked to set either the tilt board or the disk to a set of angles specified verbally by the experimenter.

\section{Method}

Subjects. Three hundred students at the University of Virginia (150 females and 150 males) participated. They were stopped as they passed by the experimenter, who was stationed near the hills, typically at their base, and asked if they would like to volunteer to participate in a short psychology experiment. All subjects were naive to the purposes of this experiment and had not participated in any prior slant experiments. None had any apparent locomotor problems.

Stimuli. Nine hills on the grounds of the University of Virginia were included in the study. Besides the requirement that there be a wide range of slopes, the following criteria were used in selecting the hills for the experiment: First, the hill needed to be near a heavy foot traffic area, owing to the nature of the method of recruiting subjects. Second, we required that it be a reasonably long hill, so that the top of the hill would be well above the horizon. And third, the hill had to have a fairly uniform and even surface, with no major changes in its inclination or bumps along its surface. The hills were always viewed from the front, in daylight, while the subjects stood at their base, and the view of the hills was unobstructed by foliage or construction of any kind.

The inclinations of the hills were $2^{\circ}, 4^{\circ}, 5^{\circ}, 6^{\circ}, 10^{\circ}, 21^{\circ}, 31^{\circ}, 33^{\circ}$, and $34^{\circ}$, as measured by a Suunto clinometer having an accuracy of $0.5^{\circ}$. All testing sites were sidewalks or walkways except for the $21^{\circ}, 31^{\circ}$, $33^{\circ}$, and $34^{\circ}$ hills, which were grassy slopes. For the $31^{\circ}, 33^{\circ}$, and $34^{\circ}$ hills, some subjects used a flight of stairs to reach the base but did not know at that time that they would be judging the inclination of the hill. The subjects were moved away from the stairs when they were asked to make their judgments so that they could not use the ratio between the riser and the tread to calculate the inclination of the hill.

Apparatus. The subjects reported their judgments in three ways: verbally, visually, and haptically. The visual judgments were made by using a disk, which consisted of an adjustable angle representing the cross-section of the inclination of a hill, with a protractor mounted at the back which allowed the experimenter to determine the angle to which the subjects set the cross-section. The subjects were free to hold the disk in any orientation they preferred, and typically they adjusted it while holding it approximately perpendicular to their line of sight. This disk is illustrated in Figure 2a. When making their visual judgments, subjects were asked to adjust the disk to the crosssection that they thought best represented the angle of inclination of the hill.

The subjects reported their haptic judgments by using a tilt board (see Figure 2b) with a flat palm rest; the tilt of the board could be adjusted upward or downward to match the pitch of the hill. The tilt board also had a protractor on its side, concealed from the observers, which allowed the experimenter to determine the angle to which it had been set. The tilt board itself was mounted on a tripod whose height could be adjusted to about waist level for each individual subject, in order to provide a comfortable position for the subjects to make their judgments. While reporting their haptic judgments, sub-

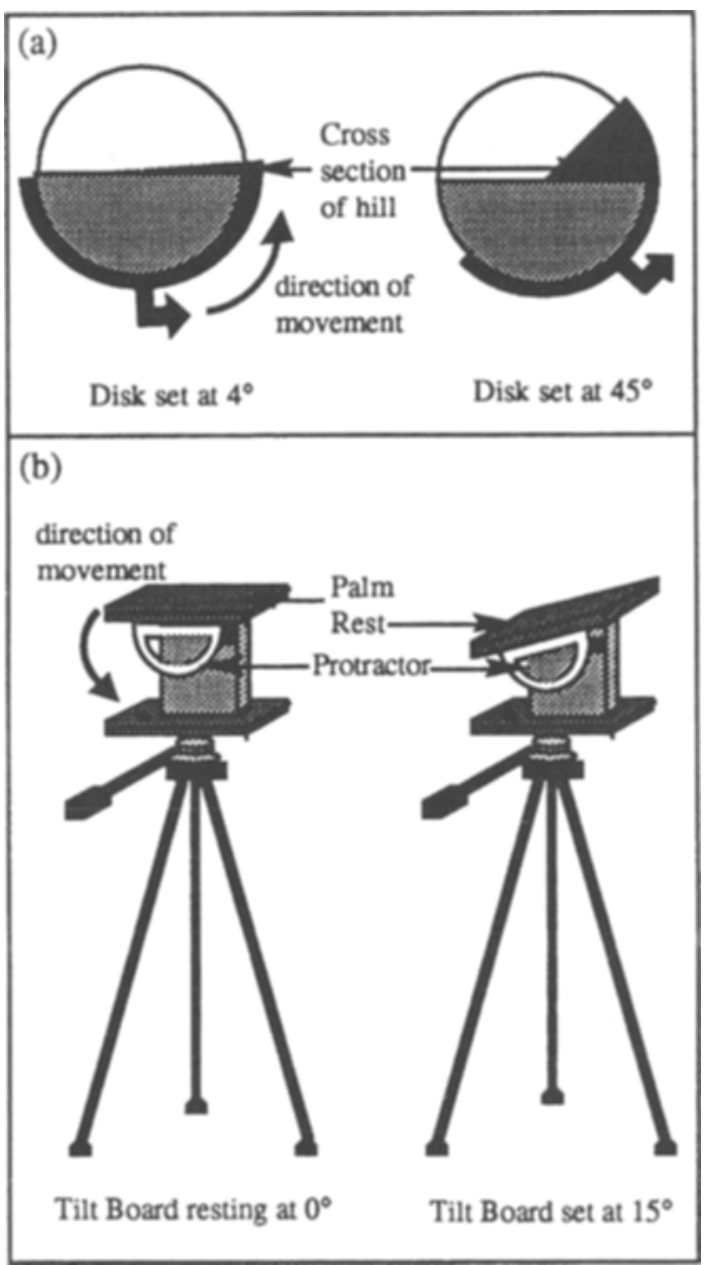

Figure 2. Measures used to report pitch judgments: (a) Disk for reporting visual judgments; (b) tilt board for reporting haptic judgments. 
jects were asked to match the tilt board to the slope of the hill before them. The tilt board was placed by their side and they always adjusted it with their dominant hand. They were not permitted to look at their hand while making the adjustments.

Design. Each subject viewed only one hill. There were 30 subjects for each hill except the $5^{\circ}$ hill, which had 60 subjects. All observers reported their judgments on each of the three measures in one of six counterbalanced orders.

Procedure. The subjects viewed the hills binocularly from the front while standing at the base of the hills. They were instructed to look directly ahead at the hill and not to attempt to obtain a side view of the hills by looking sideways. For each hill, the subjects were asked to judge the angle of inclination of the hill with respect to the horizontal, reporting their judgments on the three measures, verbal, visual, and haptic, in the counterbalanced order assigned randomly to them. The experimenter recorded their responses on paper. Feedback was not given.

The second part of the experiment tested the subjects for internal consistency in their verbal, visual, and haptic judgments. For this, subjects were asked to adjust either the tilt board or the disk to a set of verbally given angles. For all the hills except the $31^{\circ}, 33^{\circ}$, and $34^{\circ}$ hills, subjects were asked to set angles on one of the two instruments to be equal to $5^{\circ}, 10^{\circ}, 15^{\circ}$, and $20^{\circ}$. The $31^{\circ}, 33^{\circ}$, and $34^{\circ}$ hill subjects were given the following angles to adjust: $15^{\circ}, 30^{\circ}, 45^{\circ}, 60^{\circ}$, and $75^{\circ}$. The angles given to the subjects corresponded to the general range of judgments that subjects could be expected to report on the basis of earlier pilot studies. Before each angle estimate, the instrument to be used, disk or tilt board, was set to $0^{\circ}$ and the subject was asked to set it to the given angle. The angle to which the instrument was set was then recorded by the experimenter, who used the concealed protractor, and the instrument was reset to $0^{\circ}$ for the next trial The order in which the subjects were given the angles was also counterbalanced. This took a total of about $10 \mathrm{~min}$.

\section{Results and Discussion}

The data obtained for Experiment 1 are represented in two ways in Figure 3. Panel a shows the mean judgments for each of the three measures, plotted on incremental coordinates. The same data are plotted on a log-log scale in panel $b$. The $\log -\log$ plot of the data shows a linear trend within the log transformation, indicating that the curves obtained for the three measures all approximate power functions. The power function provides an excellent fit for the data: $R^{2}=.97, .99$, and .98 for the verbal, visual, and haptic measures, respectively. The power function relationship obtained between the actual pitch angle and the judged angle is consistent with what is found for magnitude estimation judgments of other psychophysical dimensions such as brightness or loudness. As with other intensity judgments, geographical pitch judgments do not correspond to an additive relationship; rather, equal stimulus ratios produce equal assessed magnitude ratios. The exponents obtained describe the following relationship between actual pitch and judged pitch: The pitch of a hill needs to be increased 3.4 times for a subject's verbal judgment to double (verbal exponent 0.564 ); 3.6 times for the visual judgment to double (visual exponent 0.543 ), and 3 times for the haptic judgment to double (haptic exponent 0.650 ).

As can be seen from Figure 3a, the subjects' verbal and visual judgments reflect large overestimations of the actual inclines. The haptic reports were far more accurate. It was revealed by $t$ tests that overall, all three measures were significantly different from the actual inclines of the hills [verbal vs. actual, $t(299)=27.13, p<.01$; visual vs. actual, $t(299)=26.25, p<.01$; haptic vs. actual, $t(299)=4.43$, $p<.01]$. Individual $t$ test analyses for each of the seven hills revealed the same results, except that for the $21^{\circ}$ and $31^{\circ}$ hills, the haptic reports were not significantly different from the actual inclines of the hills. Also, judgments on the visual and verbal measures were closely matched in the extent to which they were overestimates of the actual pitch angle of the hills. For example, for the $2^{\circ}$ hill, while subjects reported about $10^{\circ}$ both verbally and visually, they reported $5^{\circ}$ haptically. Similarly, for the $10^{\circ}$ hill, ver-
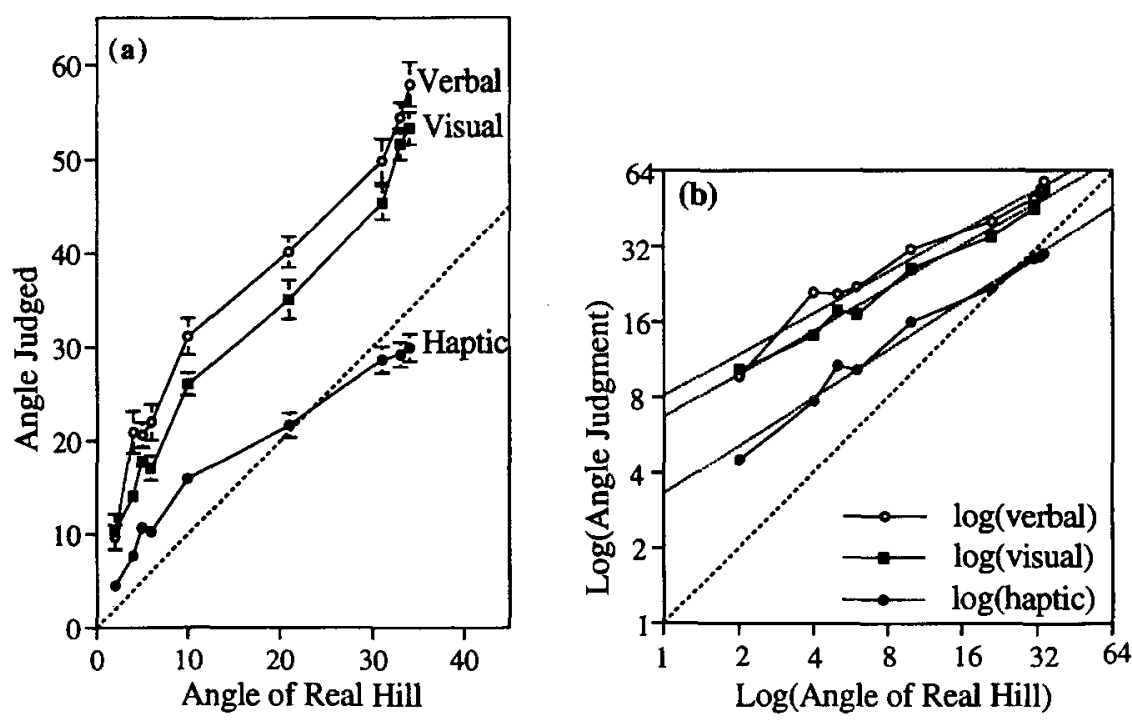

Figure 3. Mean pitch judgments reported from the base for nine hills on the verbal, visual, and haptic measures for Experiment 1: (a) on incremental coordinates; (b) on log coordinates. Exponents for the three measures were as follows: verbal, $y=8.108 x^{0.549}$; visual, $y=$ $6.675 x^{0.571}$; haptic, $y=3.298 x^{0.633}$. The dotted line indicates perfect performance. 
bal and visual judgments were closely matched $\left(31^{\circ}\right.$ and $26^{\circ}$, respectively), while the haptic judgment was more accurate $\left(16^{\circ}\right)$. For the steepest hill $\left(34^{\circ}\right)$, we see the same trend; subjects reported $55^{\circ}$ verbally, $53^{\circ}$ visually, and $29.9^{\circ}$ haptically.

A three-way analysis of variance (ANOVA: 2 levels of gender $\times 9$ hill angles $\times 3$ measures) with gender and hill angle as between-subjects factors and measure as the within-subjects factor revealed significant gender differences in hill judgments $[F(1,282)=28.72, p<.01]$ : females showed greater overestimation than did males for the inclination of the hills. The interaction between gender and measure was also significant $[F(2,564)=6.77$, $p<.01]$. Figure 4 shows the gender differences in angle estimates separately for each measure; it is apparent that gender differences were greatest for the verbal judgments. None of the higher order interactions were significant.

Figure 5 is a plot of the subjects' mean performance on the task of adjusting each of the two measures to a set of verbally given angles. Figures $5 a-5 b$ show the visual and haptic responses, respectively, to verbally given angles. As can be seen, visual responses were quite accurate; however, haptic adjustments tended to reveal underestimations of the verbally given angles.

Regression equations were applied to the visual and haptic reports made in response to the set of verbally given angles, thereby yielding a prediction of what a subject should have reported visually or haptically for a particular hill, given what he/she judged the hill to be verbally. A simple regression analysis tested how well these derived visual and haptic scores could predict the actual visual and haptic reports that subjects gave for each of the hills. Analysis revealed that the derived visual score was a good predictor of the actual reports that the subjects gave (explained variance, $R^{2}$, was .70). In the right panels of Fig- ure 5 , the actual reports are plotted against derived scores for both the visual and the haptic measures. Figure 5c presents the comparison between the actual reports and the derived scores for the visual measure. As the figure depicts and as the results also implied, subjects were consistent in their use of visual judgments; that is, the visual judgments that they made in response to the verbally given angles were nearly equivalent to the visual judgments that they made for the hills, given their verbal reports on the inclination of the hills. A similar analysis was performed for the haptic measure. In Figure 5d, the derived haptic scores are plotted against the actual haptic reports. As can be seen from the figure and as was revealed by a simple regression analysis, the actual reports and the derived haptic scores are quite well matched, in that the derived scores are good predictors of the actual reports $\left(R^{2}\right.$ or explained variance was .60).

This implies that subjects displayed an internal consistency for the verbal, visual, and haptic measures, in that they represented an angle in the same way regardless of whether it was made in the context of an observed hill or of a spoken number. This means, for example, that when facing a $10^{\circ}$ hill, people tend to say that it is about $30^{\circ}$, set the disk to about $25^{\circ}$, and adjust the palm board to about $10^{\circ}$. When verbally instructed to set the disk and palm board to $30^{\circ}$, they adjust them to approximately $25^{\circ}$ and $10^{\circ}$, respectively.

\section{EXPERIMENT 2 \\ Real Hills Viewed From the Top}

While conducting Experiment 1, we noticed that the steepest hills in our study appeared steeper from the top than from the bottom. Moreover, we realized that for the three hills greater than $30^{\circ}$, we could walk up but not walk

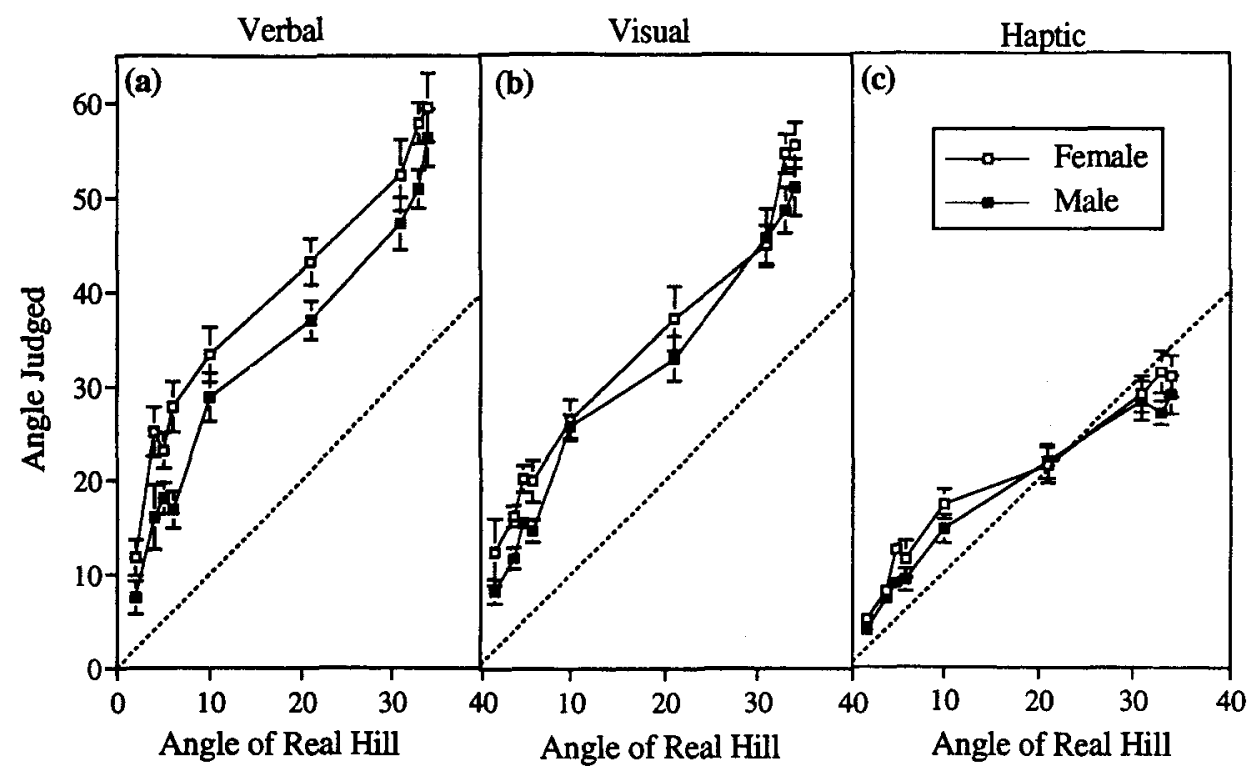

Figure 4. Gender differences in mean pitch judgments made from the base of hills for Experiment 1 : (a) verbal reports; (b) visual reports; (c) haptic reports. 

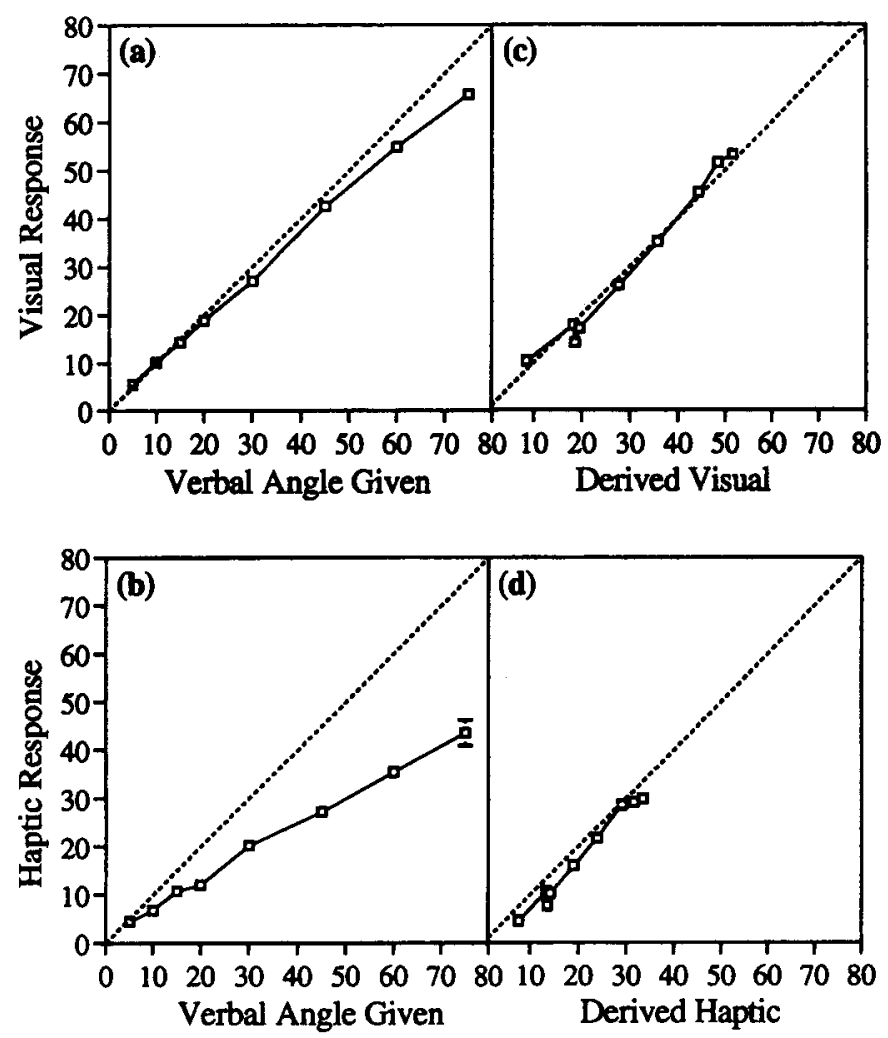

Figure 5. Internal consistency of measures for subjects in Experiment 1 : (a-b) responses to verbally given angles; $(\mathbf{c}-\mathbf{d})$ correspondence between response to verbal instruction and values derived from responses made while viewing hills.

down the grass-covered inclines without slipping and endangering ourselves. We were able to walk down all of the shallower slopes. For biomechanical reasons, there is an asymmetry in people's ability to walk up versus down steep inclines. We began to formulate a hypothesis that the perception of geographical slant relates distal inclines to our behavioral potential. By this account, these hills should look steeper from the top because our ability to traverse them depends upon whether we are attempting an ascent or descent.

This experiment was identical to Experiment 1, except that subjects stood at the top of the hills while making their pitch estimations on the three measures. The apparatus and the procedure were the same as for Experiment 1. A representative subset of the hills from Experiment 1 was used.

\section{Method}

Subjects. Two hundred ten students at the University of Virginia ( 105 females and 105 males) were recruited in the same manner as in Experiment 1. Data from 8 subjects were excluded from the analysis because the subjects were all engineers and had explicit knowledge about geographical slant from surveying courses. Their judgments were quite accurate and different from those of the naive subjects.

Stimuli. Seven hills on the grounds of the University of Virginia were viewed in daylight, while the subjects stood at the top. The in- clinations of the hills were $2^{\circ}, 5^{\circ}, 10^{\circ}, 21^{\circ}, 31^{\circ}, 33^{\circ}$, and $34^{\circ}$, and the hills were the same ones that were used in Experiment 1 .

Apparatus. The apparatus was the same as in Experiment 1. The subjects reported their judgments in three ways: verbally, visually, and haptically.

Design. The design was the same as that for Experiment 1 . There were 30 subjects for each hill.

Procedure. The procedure was the same as before.

\section{Results and Discussion}

Figure 6 presents the data obtained from Experiment 2 in two ways. Panel a shows, on incremental coordinates, the mean judgments of pitch for the three measures. The same data are plotted on a $\log -\log$ scale in panel $b$. As in Experiment 1, the data show a linear trend within the log transformation, indicating that the curves for the three measures all approximate power functions. (As before, the power function provides an excellent fit for the data: $R^{2}=.99, .99$, and .99 for the verbal, visual, and haptic measures, respectively.) The exponents obtained by fitting power functions to the curves for the three measures show the relationship between actual pitch and judged pitch to be as follows: The pitch of a hill needs to be increased 3.2 times for a subject's verbal judgment to double (verbal exponent 0.599); 3 times for the visual judgment to double (visual exponent 0.636 ), and 2.5 times for the haptic judgment to double (haptic exponent 0.764 ). 

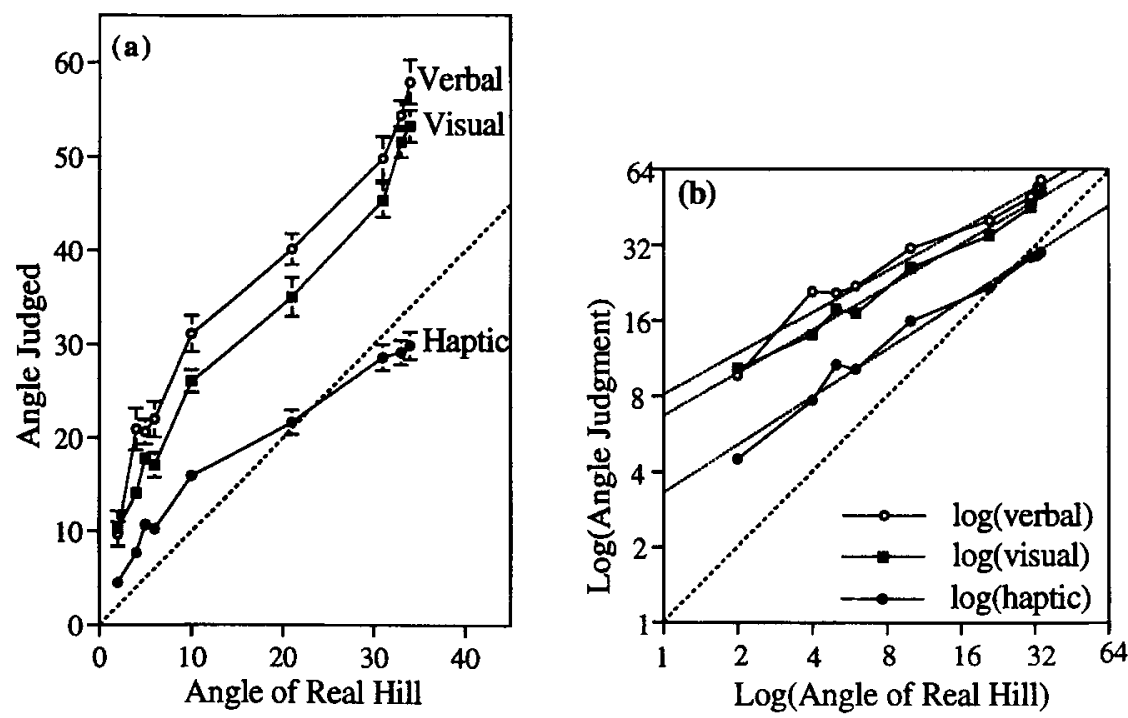

Figure 6. Mean pitch judgments reported from the top for seven hills on the verbal, visual, and haptic measures for Experiment 2: (a) on incremental coordinates; (b) on log coordinates. Exponents for the three measures were as follows: verbal, $y=7.048 x^{0.599}$; visual, $y=$ $5.895 x^{0.636}$; haptic, $y=2.546 x^{0.764}$.

As in Experiment 1, the verbal and visual judgments reflected large overestimations of the actual inclines; the haptic reports were far more accurate. It was revealed by $t$ tests that overall, all three measures were significantly different from the actual inclines of the hills [verbal vs. actual, $t(209)=25.18, p<.01$; visual vs. actual, $t(209)=$ $23.82, p<.01$; haptic vs. actual, $t(209)=9.53, p<.01]$. Individual $t$ test analyses for each of the seven hills revealed the same results for all except the $33^{\circ}$ hill, where the haptic report was not significantly different from the actual incline of the hill. Also, as before, judgments on the visual and verbal measures were closely matched in the extent to which they were overestimates of the actual pitch angle of inclination of the hills.

A three-way ANOVA ( 2 levels of gender $\times 7$ hill angles $\times 3$ measures, with gender and hill angle as betweensubjects factors and measure as the within-subjects factor) revealed significant gender differences in hill judgments $[F(1,196)=9.04, p<.01]$, with females showing greater overestimation than males for the inclination of all the hills. The interaction between gender and measure was also significant $[F(2,392)=6.93, p<.01]$. As is apparent in Figure 7 , gender had its greatest effect on the verbal judgments. None of the higher order interactions were significant.

Figure 8 (panels $a-b$ ) shows the mean visual and haptic responses to verbally given angles. As in Experiment 1 , visual responses tended to be quite accurate, whereas haptic responses tended to underestimate the angles given.

Regression equations were obtained from the subjects' angle judgments on the visual and haptic measures and were used to calculate derived visual and haptic scores. A simple regression analysis revealed that the derived visual and haptic scores could accurately predict the actual visual and haptic reports that subjects gave for each of the hills quite well (explained variance, $R^{2}$, was .89 for the visual measure, and .75 for the haptic measure). In panels c-d of Figure 8, the actual reports are plotted against derived scores for both the visual and the haptic measures. As can be seen in the figure and as the results also implied, subjects were consistent in their visual and their haptic judgments, meaning that the judgments that they made in response to the verbally given angles were nearly equivalent to the judgments that they made for the hills, given their verbal reports on the inclination of the hills.

\section{COMPARISON OF EXPERIMENTS 1 AND 2}

Figure 9 presents a comparison of the judgments made by the subjects viewing from the base (Experiment 1) and those viewing from the top of the hills (Experiment 2). The figure shows an effect of viewpoint on all three measures. A three-way ANOVA ( 2 levels of gender $\times 7$ hill angles $\times 2$ viewpoints) revealed significant gender effects for all the three measures $[F(1,422)=26.46, p<.01$, verbal; $F(1,422)=14.51, p<.01$, visual; $F(1,422)=3.52$, $p<.05$, haptic]. The effect of viewpoint was significant for the visual and haptic measures $[F(1,422)=6.24, p<$ .01 , visual; $F(1,422)=31.96, p<.01$, haptic], but not for the verbal measure $[F(1,422)=1.81, p<.18]$.

By far the most interesting result was the interaction between viewpoint and hill angle, which was significant for all the three measures $[F(6,422)=2.25, p<.05$, verbal; $F(6,422)=2.78, p<.05$, visual $F(6,422)=7.41, p<.01$, haptic]. The interaction between hill pitch and viewpoint implies that subjects tended to respond differently to different hills, depending on whether they had an uphill or a downhill view. For the hills with the smallest slants, subjects perceived their inclination to be either the same from 


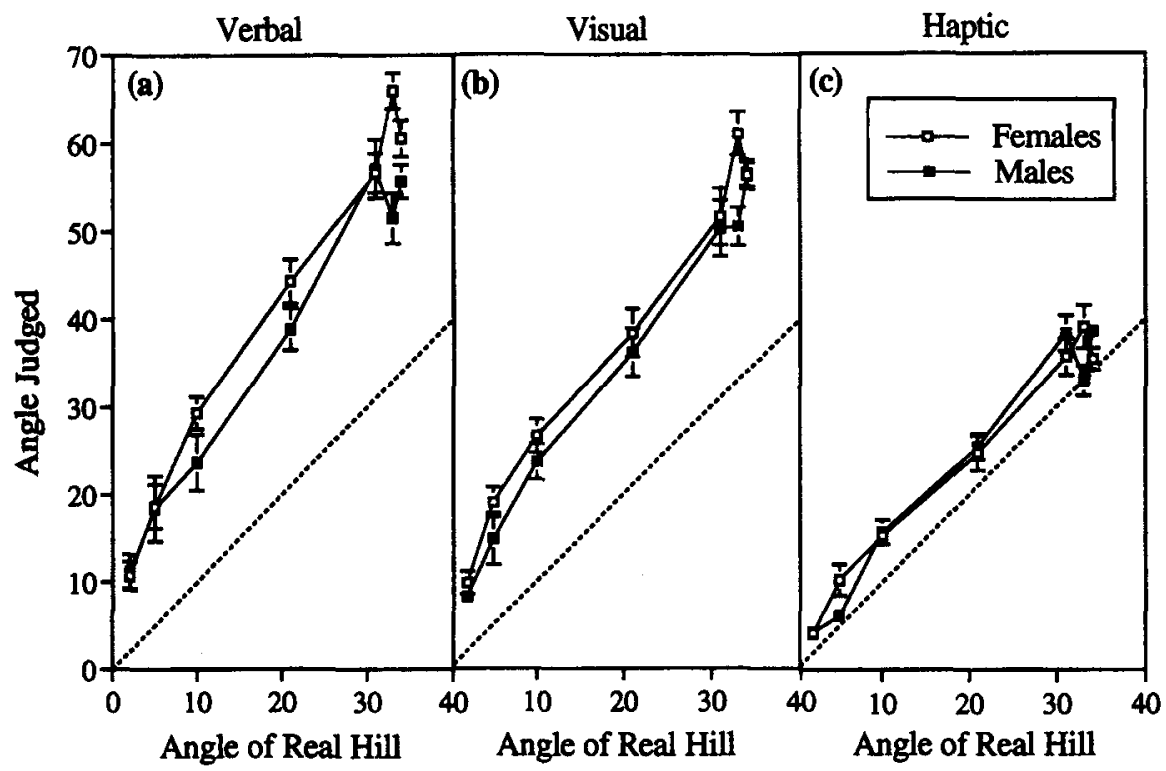

Figure 7. Gender differences in mean pitch judgments made from the top of hills for Experiment 2: (a) verbal reports; (b) visual reports; (c) haptic reports.
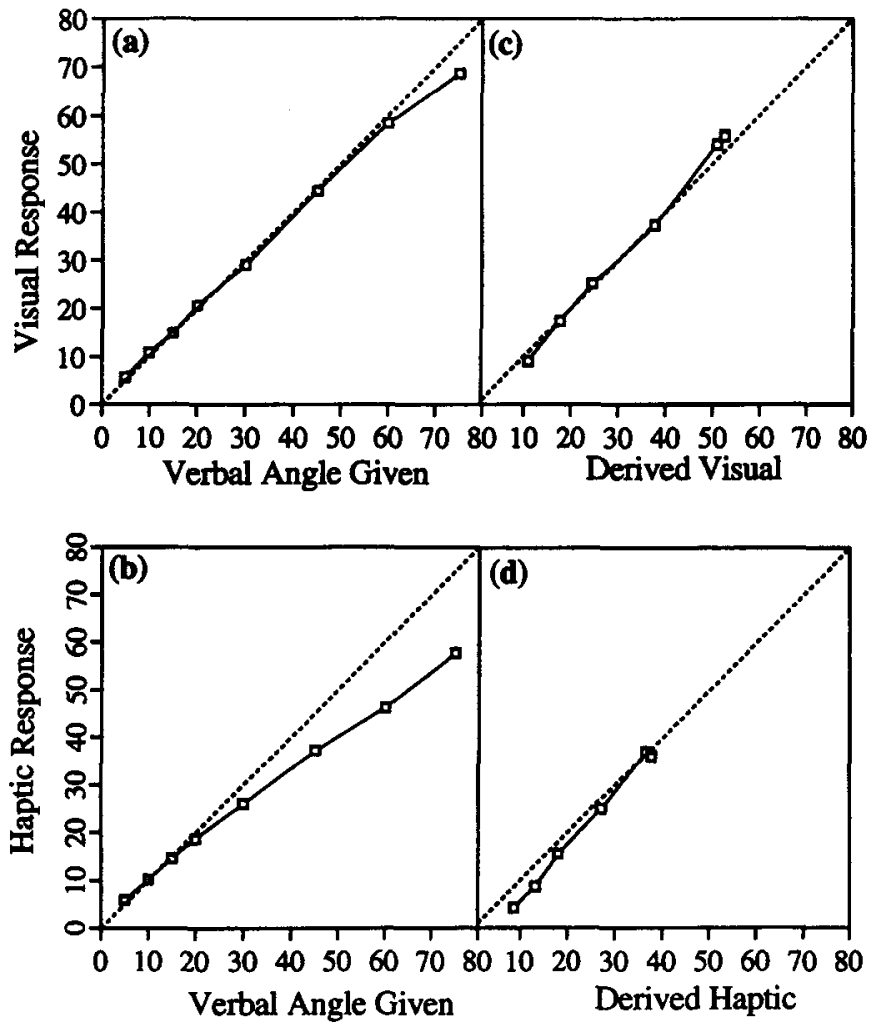

Figure 8. Internal consistency of measures for subjects in Experiment 2: (a-b) responses to verbally given angles; $(\mathbf{c}-\mathbf{d})$ correspondence between response to verbal instruction and values derived from responses made while viewing hills. 


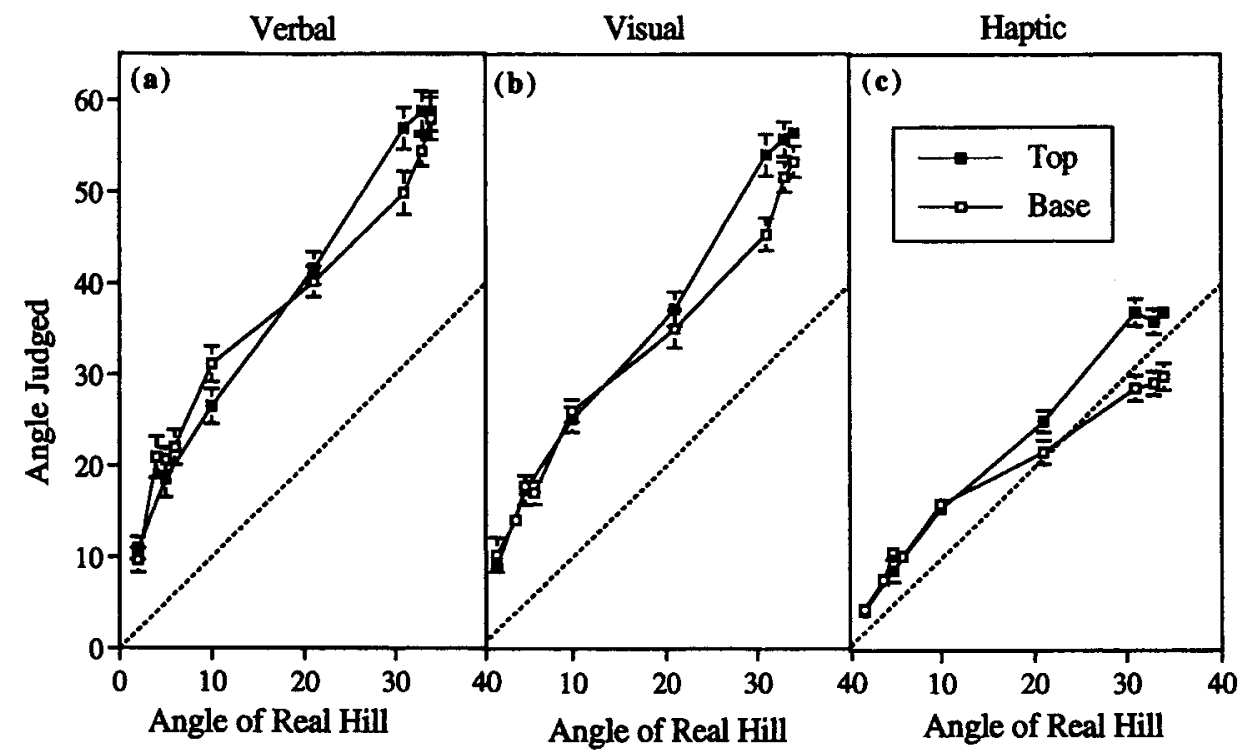

Figure 9. Comparison of mean pitch judgments made from the top and the base: (a) verbal reports; (b) visual reports; (c) haptic reports.

the top and base or steeper from the base. On the other hand, for the three steepest hills, subjects tended to perceive the pitch as greater when they judged it from the top than when they judged it from the base.

We had expected that the steepest hills would be judged as steeper on verbal and visual measures when viewed from the top, owing to the asymmetry in people's ability to ascend, as opposed to descend, these slopes. However, the effect of viewpoint on the haptic measure was unanticipated. If the haptic measure of geographical pitch is unaffected by factors such as the effort involved in ascending or descending a slope, subjects' haptic adjustments should not have been affected by viewpoint. It could be that the biomechanical motions involved in adjusting the tilt board were easier with the downhill than with the uphill setting. With more ease of movement at the wrist, subjects may have been able to adjust the tilt board to significantly higher angles with the downhill setting. It is also possible that viewpoint's influence on haptic adjustments were real and due to unknown factors.

\section{EXPERIMENT 3}

\section{Hills Viewed From the Base in Virtual Reality}

In order to obtain normative data on geographical pitch perception over a wider range of hills than could be conveniently found out-of-doors, in this experiment we created a virtual reality (VR) display. VR presents a computergenerated interactive environment to the observer, using a head-mounted display (HMD). Small monitors are mounted inside the headset, providing a stereo display. Observers can move their heads and walk around while wearing the HMD. As they move, the location and orientation of their heads are tracked, and the system changes its imagery to present a stable simulated environmental layout accord- ingly. As opposed to viewing a computer terminal's screen, in VR observers perceive themselves as being inside the scene. Subjects provided their slant judgments on two of the three measures used in Experiment 1: verbal and haptic. Over the range of inclinations that were assessed in Experiments 1 and 3, the pitch judgments obtained were highly similar.

\section{Method}

Subjects. Twenty University of Virginia students ( 9 females and 11 males) with normal or corrected-to-normal vision participated in the experiment. All were naive to the purposes of this experiment and had not participated in any prior slant experiments. Subjects were recruited by word of mouth and by an announcement on the university's electronic mail network, calling for volunteers to participate in the experiment in exchange for experiencing VR.

Stimuli. Twelve hills ranging from $5^{\circ}$ to $60^{\circ}$ at $5^{\circ}$ increments were simulated in VR. The subject's viewpoint was at the base of the hills. Each display, presented in color, consisted of a grassy hill with a black and white checkerboard road running up the middle. The subject and the hill were placed on a large surrounding ground plane with the horizon clearly in view against a sky blue background. The dimensions of the real $5^{\circ}$ hill used in Experiment 1 were used to simulate the hills in VR. Each hill was $30 \mathrm{~m}$ wide, with the checkerboard road covering the central $10 \mathrm{~m}$. A post was located at the base of the hill, $10 \mathrm{~m}$ from the right side. Its position in the VR environment corresponded to the location of the tilt board in the real world. The distance along the visible surface of the hill (hypotenuse) was kept constant at $100 \mathrm{~m}$, while the height of the hill (rise) and depth of the hill (run) varied as a function of the slant angle. Each simulation took the angle and the length of the slope as the input and computed rise and run as follows:

$$
\begin{aligned}
& \text { run }=\cos (\text { angle }) \times \text { hypotenuse } \\
& \text { rise }=\sin (\text { angle }) \times \text { hypotenuse }
\end{aligned}
$$

Apparatus. The stimuli were generated on two Silicon Graphics VGX computers (each capable of rendering up to $1,000,000$ polygons per second). The subjects used a VPL HMD, which received an NTSC (television) signal from the computers. The HMD consisted 
essentially of two small monitors, each of which presented a stereoappropriate image to each eye. Effective resolution for each monitor was $185 \times 139$ pixels, and the total field of view was $90^{\circ}$. Robinett and Rolland (1991) provide a detailed description of the VPL display system. LEEP optics lenses were used to collimate the light and to allow accommodation to the image. A Polhemus magnetic tracker was placed on the HMD to detect the observer's head position in $x, y, z$ space and its pitch, yaw, and roll orientation. The application provided texture gradient and perspective cues, stereo and motion parallax information, and Gouraud shading. The subjects reported their judgments on two measures: verbal and haptic. The haptic judgments were reported on the same tilt board that was used in Experiment 1. (The visual measure used in the previous experiments could not be used, since subjects were wearing the HMD.)

Design. Each subject saw all of the hills, in random order. All observers reported their judgments on both of the two measures, first verbally and then using the tilt board. Since the dimensions of the real $5^{\circ}$ hill used in Experiment 1 were identical to the $5^{\circ}$ hill shown in VR, we were interested in comparing subjects' responses to these two hills. For this purpose, subjects were shown the $5^{\circ}$ hill in VR four times in the experimental session, whereas the other angles were presented only once.

Procedure. Subjects were first introduced to the VR environment with a brief demonstration to familiarize them with the hardware and the immersive VR experience. Then the experimental display was described to them and they were placed in that environment. Once they were familiar with the environment, they were asked to look up at the hill and report verbally what the pitch angle of the hill appeared to be. They were then asked to adjust the tilt board to make it match the incline that they saw. After the subjects had provided their judgments on both measures, and before the next stimulus appeared, a blue "virtual curtain" was lowered to block the subjects" view and lifted once the new simulated environment was ready. The VR subjects were encouraged to look around and to move back and forth laterally by approximately a meter, in order to ground themselves in the simulated environment and to notice the ground plane (horizon) while making their judgments.

As in Experiment 1, after the subjects had made the hill judgments, they were asked to adjust the tilt board to a set of angles ranging from $5^{\circ}$ to $60^{\circ}$ at $5^{\circ}$ intervals. For each of the angle estimates, the tilt board was initially set to $0^{\circ}$ before the subject set it to a given angle. The order in which the subjects were given the angles was the same random order as that of the hills that they had seen; for example, if a subject first saw a $5^{\circ}$ hill followed by a $40^{\circ}$ hill, then he/she would be asked to set the tilt board first to $5^{\circ}$ and then to $40^{\circ}$.

\section{Results and Discussion}

The mean judgments for the VR hills on the verbal and haptic measures are shown in Figure 10. Panel a shows the mean judgments of the subjects on an incremental scale and panel $b$ is the log-log transform of the same data. As can be seen in Figure 10a, subjects tended to overestimate the pitch of the hills represented in the VR environment as assessed by verbal but not by haptic judgments. It was revealed by $t$ tests that overall, the two measures differed significantly from the actual inclines of the hills. As before, the verbal reports for the 12 angles were overestimations of the actual pitch $[t(11)=20.15, p<.01]$. On the other hand, the haptic reports were underestimations $[t(11)=$ $2.79, p<.05]$. As with the findings of Experiment 1, both the verbal and the haptic measures approximated power functions $\left(R^{2}=.99\right.$ for verbal and .94 for haptic). The exponent obtained for the verbal measure for VR hills $(0.590)$ was very similar to that obtained for the verbal measure for the real hills in Experiment 1 (0.564), again indicative of the fact that the pitch of the VR hills needed to be increased 3.4 times for subjects to say that it had doubled. The exponent for the haptic measure was higher $(0.740)$, meaning that pitch needed to increase by 2.6 times before subjects judged the hill to have doubled in pitch when assessed haptically.

Across all angles, there was an extremely close correspondence between the judgments made out-of-doors and in VR. Figure 1 la shows the comparison between the VR and real hills on the verbal measure, and Figure $11 \mathrm{~b}$ shows
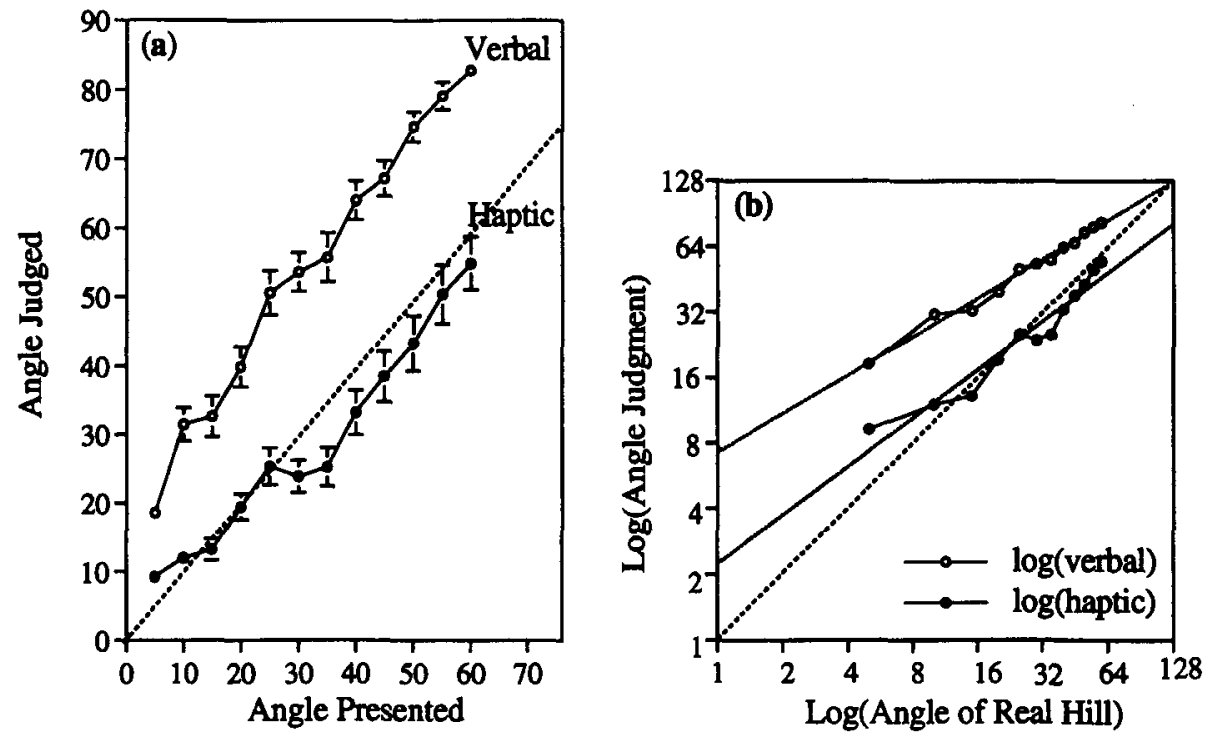

Figure 10. Mean pitch judgments reported from the base for 12 virtual reality hills on the verbal and haptic measures for Experiment 3: (a) on incremental coordinates; (b) on log coordinates. Exponents for the two measures were as follows: verbal, $y=7.228 x^{0.590}$; haptic, $y=2.233 x^{0.740}$. 
this comparison for the haptic measure. As the figure reveals, the regression functions yielded very similar parameters for both the verbal measure (real hills, $8.11 x^{0.59}$; VR hills, $7.23 x^{0.59}$ ) and the haptic measure (real hills, $3.30 x^{0.65}$; VR hills, $2.23 x^{0.74}$ ). Note that the obtained intercepts and exponents are very close across the two types of displays.

VR subjects reproduced a set of verbally given angles on the palm board, and these angle adjustments are plotted in Figure 12a. As can be seen and as was also revealed by a $2 \times 2$ ANOVA ( 2 levels of gender $\times 2$ types of displays), there is a good match between the angle judgments given by the VR subjects and those given by the subjects who judged the real hills. No significant gender differences were obtained.

Like the angle judgments given by the subjects in the previous experiments, the haptic reports given by the subjects in response to the set of verbally given angles were used to obtain derived haptic scores, scores that the subjects should have reported given what they judged the inclination of the VR hills to be verbally. A simple regression analysis revealed that the actual reports and the derived scores were well matched $\left(R^{2}=.66\right)$, as can be seen in Figure 12b. This indicates that the subjects were internally consistent in their verbal and haptic adjustments. They made similar haptic adjustments to verbally given angles and to visually presented hills that evoked the same verbal pitch judgment.

\section{EXPERIMENT 4}

\section{Hills Viewed From the Top in Virtual Reality}

This experiment was identical to Experiment 3, except that the subject's simulated viewpoint was changed to that of a person standing at the top of the hill, looking down. There were three main purposes of this experiment. The first was to obtain pitch angle judgments from the tops of hills for inclinations not readily available in the real world. The second was to assess the correspondence between the judgments for real hills and those presented in VR. Finally, the primary purpose of this experiment was to determine whether viewpoint would interact with pitch judgments as it had across Experiments 1 and 2. Would the steepest hills look steeper from the top than from the bottom?

\section{Method}

Subjects. Twenty University of Virginia students ( 10 females and 10 males) participated in the experiment as part of a requirement for an introductory psychology course. All had normal or corrected-tonormal vision. They were naive to the purposes of this experiment and had not participated in any prior slant experiments.

Stimuli. The stimuli were the same as those used in Experiment 3, except for minor changes in the display. We used the same 12 hills ranging from $5^{\circ}$ to $60^{\circ}$ at $5^{\circ}$ increments, now from the viewpoint of a person standing at the top of the hill looking down. The post was located at the top of the hill to the right, and its position again corresponded with the location of the tilt board in the real world. A departure from the previous experiment was the presence of a number of vertical black posts scattered randomly on the grassy portions of the hill; the purpose behind this was to provide subjects with a clear indication of the vertical.

Apparatus. The stimuli were generated on one Silicon Graphics Onyx Reality Engine2 (capable of rendering up to 1,000,000 polygons per second). The subjects used a Virtual Research HMD, which received an NTSC (television) signal from the computer. The resolution and field of view for this system were the same as for the VPL system used in the previous experiment.

Design. The design was the same as that for Experiment 3, except that each subject viewed the hills from the top, instead of from the base.

Procedure. The procedure was the same as that for Experiment 3.

\section{Results and Discussion}

Figure 13 shows the mean judgments for the VR hills on the verbal and haptic measures. As Figure 13a shows, subjects tended to overestimate the pitch of the hills repre-

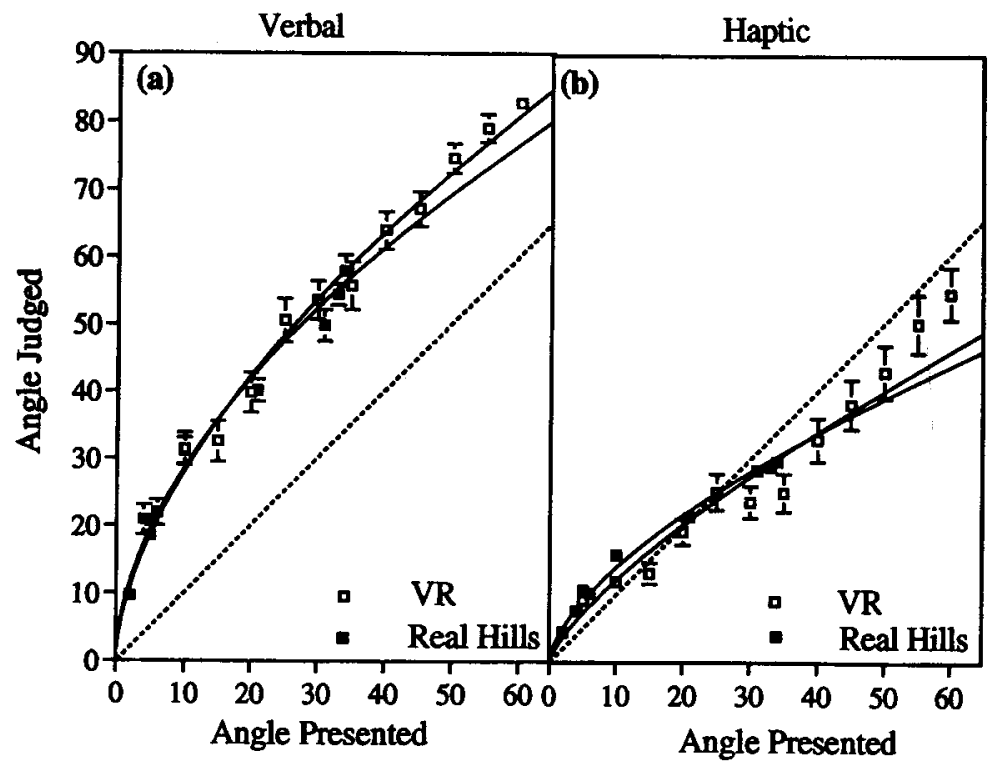

Figure 11. Judgments for real hills and VR hills compared: (a) verbal reports; (b) haptic reports. 


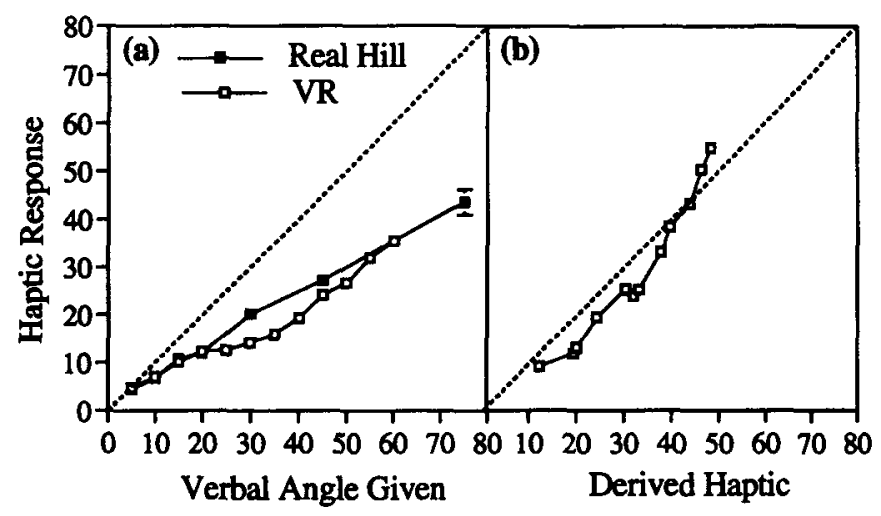

Figure 12. Internal consistency of measures for subjects in Experiment 3: (a) responses to verbally given angles; (b) correspondence between response to verbal instruction and values derived from responses made while viewing hills.

sented in the VR environment when making verbal judgments but not when making haptic judgments. It was revealed by $t$ tests that overall, the verbal reports for the 12 angles differed significantly from the actual inclines of the hills $[t(11)=7.4, p<.01]$, whereas the haptic reports were quite accurate and did not differ significantly $[t(11)=1.39$, $p<.19]$.

As with the findings of the previous three experiments, both the verbal and the haptic measures approximated power functions $\left(R^{2}=.95\right.$ for verbal and .97 for haptic; Figure $13 \mathrm{~b}$ ). The exponent obtained for the verbal measure was 0.798 , indicative of the fact that the pitch of the VR hills needed to be increased 2.4 times before subjects said it had doubled. The exponent for the haptic measure was 0.807 , implying again that pitch needed to be increased by 2.4 times in order for subjects to judge it as having doubled.
Again, there was a close correspondence between the judgments made out-of-doors and in VR. Figure 14a shows the comparison between the VR and real hills for the verbal judgments, and Figure $14 \mathrm{~b}$ shows the comparison for the haptic judgments. The parameters obtained from fitting regression functions to the data from the real hills and VR hills were again very similar on the haptic measure: $2.56 x^{0.76}$ for the real hills and $2.75 x^{0.81}$ for the VR hills. The verbal measure, on the other hand, did show an effect of viewing condition, reflected in the parameters obtained: $7.05 x^{0.60}$ for the real hills and $2.67 x^{0.80}$ for the VR hills. The difference between the verbal reports in the two viewing conditions is attributable to slightly smaller judgments for the $10^{\circ}, 15^{\circ}$, and $20^{\circ}$ inclines in VR.

As in Experiment 3, the subjects produced a set of verbally given angles on the palm board. As can be seen in
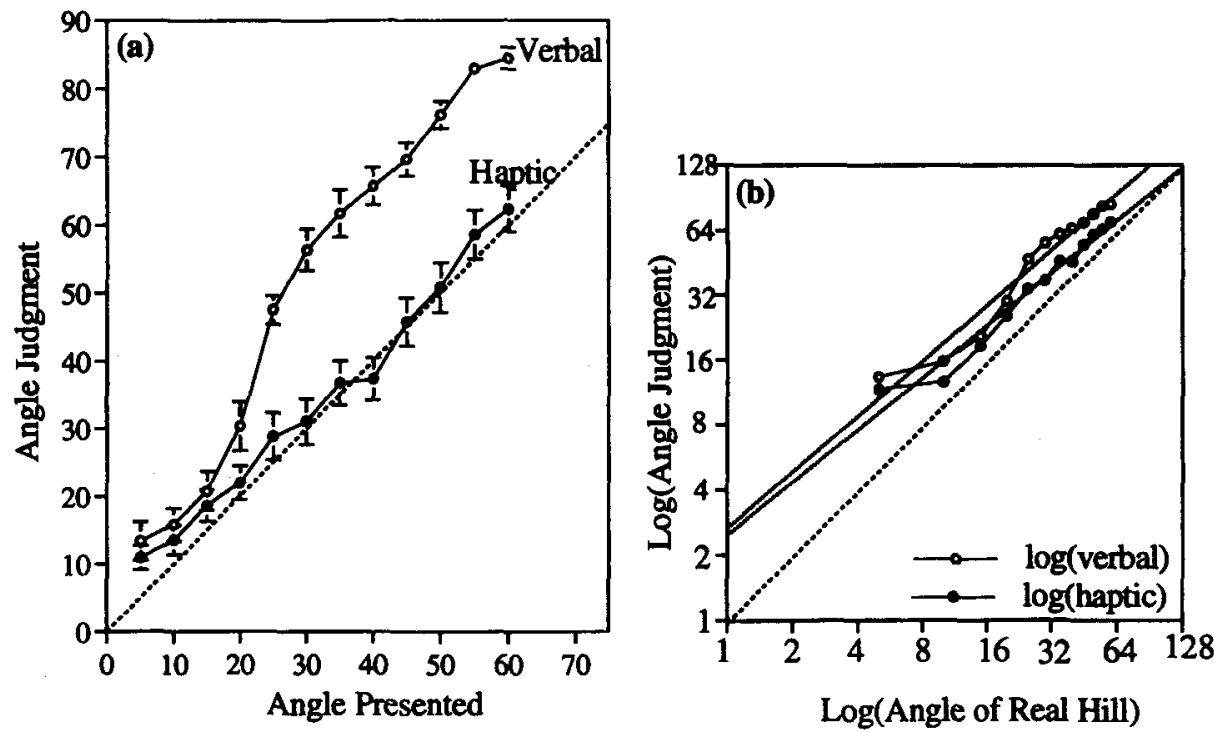

Figure 13. Mean pitch judgments reported from the top for 12 virtual reality hills on the verbal and haptic measures for Experiment 4: (a) on incremental coordinates; (b) on log coordinates. Exponents for the two measures were as follows: verbal, $y=3.435 x^{0.798}$; haptic, $y=2.475 x^{0.807}$. 


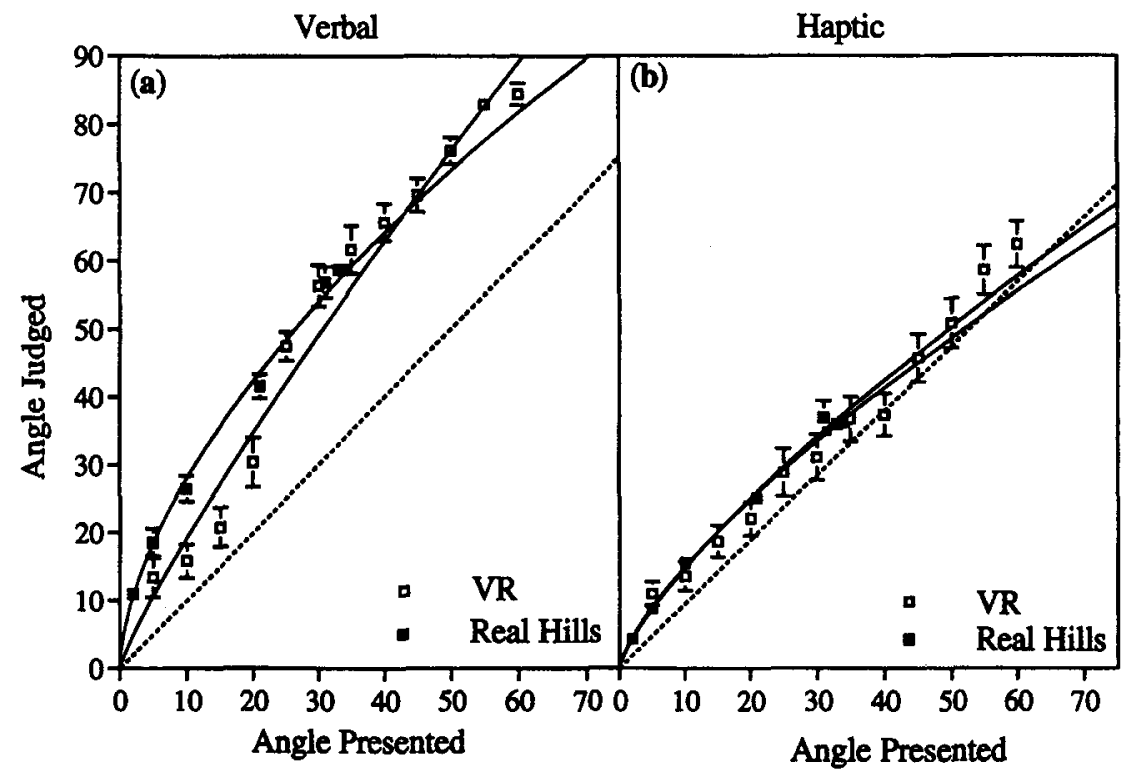

Figure 14. Judgments for real hills and virtual reality hills compared: (a) verbal reports; (b) haptic reports.

Figure 15 a, and as revealed by a $2 \times 2$ ANOVA ( 2 levels of gender $\times 2$ types of displays), there is a good match between the angle judgments given by the VR subjects and those given by the subjects who judged the real hills. No significant gender differences were obtained.

The haptic adjustments made by the subjects in response to the set of verbally given angles were used to obtain derived haptic scores, scores that the subjects should have reported given what they judged the inclination of the VR hills to be verbally. A simple regression analysis revealed that the actual reports and the derived scores were well matched $\left(R^{2}=.69\right.$; Figure $\left.15 \mathrm{~b}\right)$. This implies that haptic responses were consistent with the verbally given angles. Verbal instructions evoked haptic adjustments similar to those made in the context of simulated hills that elicited the same verbal angle responses.

\section{COMPARISON OF EXPERIMENTS 3 AND 4}

Figure 16 shows a comparison of the judgments made in VR by the subjects viewing hills from the top and from the base. The figure reveals that there was an effect of viewpoint on both measures, verbal and haptic. This effect can be seen in the results from a three-way repeated measures ANOVA ( 2 levels of gender $\times 2$ viewpoints $\times 2$ measures, with gender and viewpoint as between-subjects factors and measure as the within-subjects factor). This analysis revealed two significant two-way interactions and one threeway interaction. The interaction between hill pitch and viewpoint $[F(11,36)=2.46, p<.05]$ implied that subjects tended to respond differently to different hills, depending on whether they had an uphill or downhill view. The interaction between measure and viewpoint $[F(1,36)=14.13$, $p<.01]$ implied that the verbal and haptic measures tended to interact differently with the viewpoint variable. This in- teraction was further clarified by the interaction of measure, viewpoint, and hill pitch $[F(11,36)=4.34, p<.01]$, which implied that the interaction of hill pitch and viewpoint was more potent for the verbal reports than for the haptic ones (cf. Figure 16).

As with the findings for the real hills, verbal judgments for the less steep hills were the same from the top and base, or steeper from the base. For steeper hills, subjects tended to judge the same hill to be more steep if they viewed it from the top than from its base. Like the subjects who viewed the real hills, subjects in VR also appear to be influenced by a hill's climbability, despite the artificial environment. At about the angle where hills can no longer be descended, around $30^{\circ}$ in the real world, hills in VR were verbally judged to be steeper from the top than from the base.

For the haptic reports, subjects tended to judge the hills as steeper from the top, regardless of the pitch of the hill. As was the case in the experiments involving real hills, the influence of viewpoint on the haptic measure is not easy to explain. It is not known whether it was due to differential ease in adjusting the palm board across the two viewpoints, or to the effect of some variable that caused a genuine change in haptic perception.

\section{EXPERIMENT 5 \\ The Effect of Fatigue on Perceiving Geographical Slant}

If the perception of geographical slant relates our behavioral potential to the distal inclination of hills, then hills ought to look steeper when we are tired than when we are not. In Experiment 5, we tested this possibility and found it to be true. Subjects in this study judged the pitch of one hill, went on an exhausting run, and then judged the pitch 


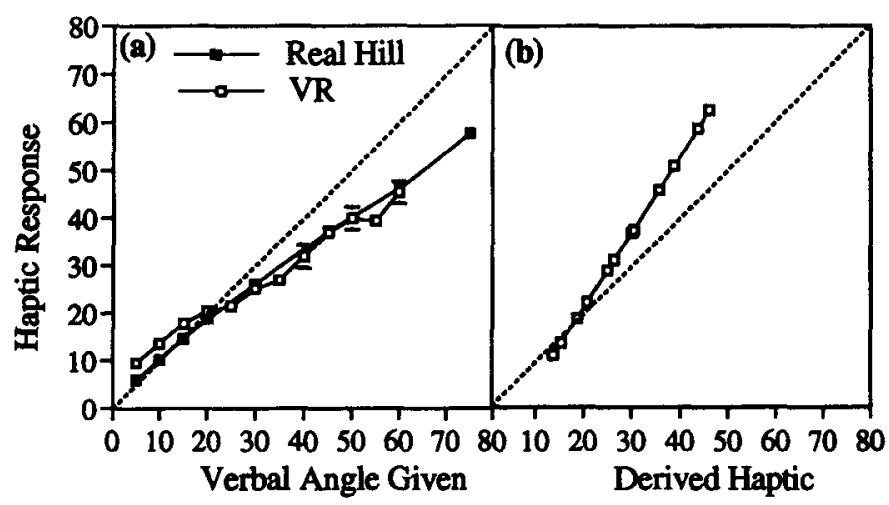

Figure 15. Internal consistency of measures for subjects in Experiment 4: (a) responses to verbally given angles; (b) correspondence between response to verbal instruction and values derived from responses made while viewing hills.

of a second hill. When tired, subjects reported a greater pitch on the verbal and visual measures than on the haptic one.

\section{Method}

Subjects. The subjects were 60 University of Virginia students (30 females and 30 males). All had normal or corrected-to-normal vision and ran or jogged for exercise at least three times a week for at least 3 miles per run. Subjects were recruited from an introductory psychology course on the basis of a questionnaire and were given class credit for participation. All were naive to the purposes of this experiment and had not participated in any prior slant experiments. All subjects were asked at the end of the experiment if they had any prior knowledge about the tendency to overestimate hills. On the basis of these answers, the data from 4 subjects were excluded from the final analyses-a skier from Switzerland and three civil engineering students, who volunteered information about knowing about the tendency to overestimate the pitch of hills and said that they had taken this knowledge into account while reporting their judgments. Three additional subjects were omitted from analyses. They were varsity soccer players, conditioned athletes who ran up hills as part of their training. They did not appear to show any signs of exhaustion at the end of their runs and reported that they were not tired.

Stimuli. Two hills $\left(5^{\circ}\right.$ and $\left.31^{\circ}\right)$ were used for this experiment. The $5^{\circ}$ hill was different from the $5^{\circ}$ hill used in Experiments 1 and 2, but its selection was based on the same criteria as those for the hills in those experiments. The $31^{\circ}$ hill was that used in Experiments 1 and 2 .

Apparatus. The apparatus was the same as that in Experiment 1.

Procedure. The procedure for this experiment was similar to that in Experiment 1, except that in the present instance the subjects judged both hills, one before and one after their runs. The subjects were told that they would be required to go on a run of their choice and would be answering questions both at the beginning and at the end of their runs. They would be given the starting and finishing points for their runs, which were the $5^{\circ}$ hill and the $31^{\circ}$ hill, respectively, for half the subjects and the $31^{\circ}$ hill and the $5^{\circ}$ hill for the other half, though the subjects were not told specifically that these points would be at hills. There were no constraints on the subjects regarding the length, route, or duration of their runs, the only requirement being that they be very tired when they reached the finishing point. Subjects were taken to the base of the starting hill and were asked a set of distractor questions. As it was presented to the subjects, the ex-

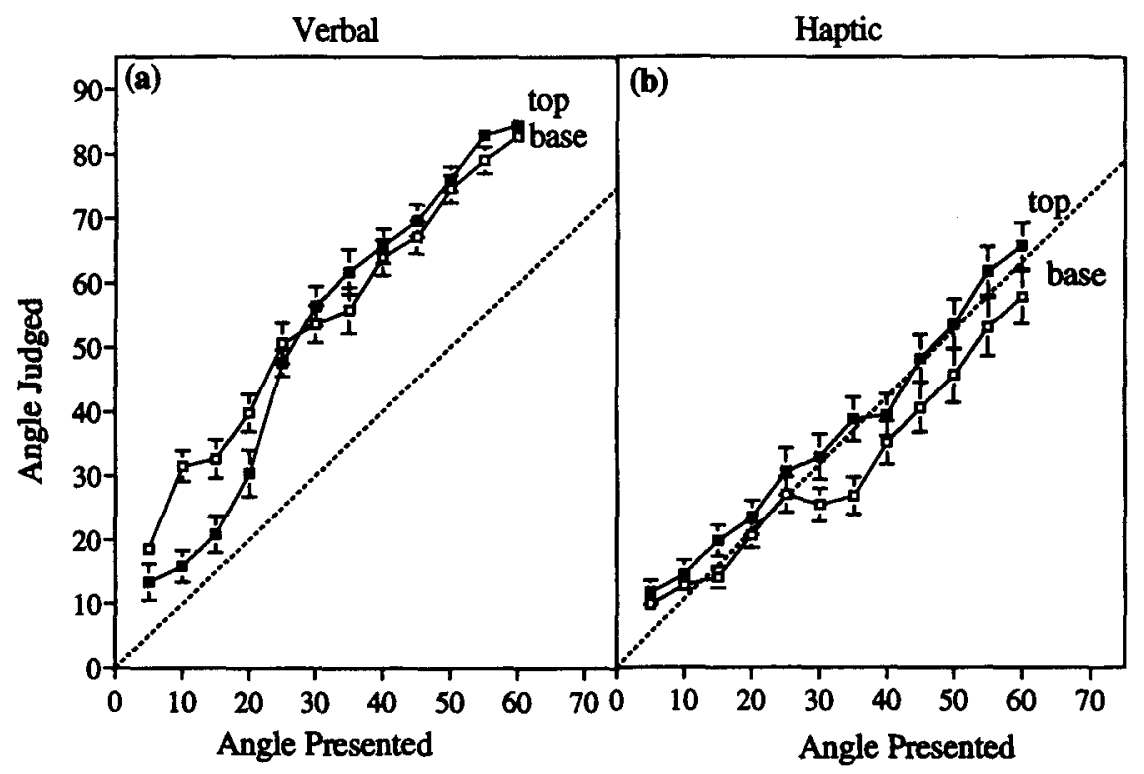

Figure 16. Comparison of mean pitch judgments made for virtual reality hills from the top and the base: (a) verbal reports; (b) haptic reports. 
periment was not about geographical slant perception, but rather about the decisions that people used to choose their running routes. They were asked various questions about the length of average runs, and the number of hills encountered and their inclinations. These questions were used in order to prevent the subjects from thinking about the inclination of hills while going on their runs. In the context of these other questions, they were asked to judge the inclination of the hill before them on each of the three measures, in one of several counterbalanced orders. After that, they started off on their runs. On completing their runs, they were met by the experimenter at the base of the finishing hill and were again asked some brief distractor questions before judging the inclination of that hill.

\section{Results and Discussion}

Figure 17 compares the judgments given by the subjects for the two hills before and after their runs, for the three measures, verbal, visual, and haptic. As is indicated in Figure $17 \mathrm{a}$, verbal and visual estimates about the inclination of the $5^{\circ}$ hill were greater for the subjects who had just completed their runs. A two-way ANOVA ( 2 levels of gender $\times 2$ orders) indicated that the difference between the verbal pitch judgments before and after the run was significant $[F(1,49)=9.03, p<.01]$, as was the case for the visual judgments $[F(1,49)=39.43, p<.01]$. The haptic judgments did not change significantly from before to after the run $[F(1,49)=3.37, p<.07]$. As is shown in Figure $17 \mathrm{~b}$, similar results were obtained for the $31^{\circ}$ hill. There were significant changes in the verbal and visual reports for subjects tested before or after the run $[F(1,49)=12.20$, $p<.01$ and $F(1,49)=4.36, p<.05$, respectively]. The haptic judgments were unaffected by the running manipulation $[F(1,49)=0.29, p<.59]$. No gender differences were obtained overall for judgments for the $5^{\circ}$ and $31^{\circ}$ hills, or for change in judgments for inclines from before the run to after.

The average increase in perceived pitch due to the running manipulation for the $5^{\circ}$ hill was $6.82^{\circ}(35 \%)$ for the verbal measure and $8.86^{\circ}(50 \%)$ for the visual measure. For the $31^{\circ}$ hill, the average increase was $11.36^{\circ}(24 \%)$ for the verbal measure and $5.71^{\circ}(12 \%)$ for the visual measure.
The judgments that the subjects made for the two hills were compared with the reports obtained for the hills in Experiment 1 . It was revealed by $t$ tests that there were no significant differences between the judgments of the subjects in Experiment 1 and those given by the subjects in this experiment who judged the hills before going on their run, for both the $5^{\circ}$ and the $31^{\circ}$ hills. On comparing the judgments given by the subjects who judged the hills after their runs with the judgments given by the subjects of Experiment 1 , we found significant differences for the $5^{\circ}$ hill on the verbal and visual measures [verbal, $t(82)=2.43$, $p<.05$; visual, $t(82)=5.48, p<.01]$ but not the haptic judgments $[t(82)=.24, p<.81]$. Similarly, for the $31^{\circ}$ hill, significant differences were found for the verbal and visual judgments but not for haptic judgments [verbal, $t(52)=$ $2.55, p<.05$; visual, $t(52)=3.25, p<.01$; haptic, $t(52)=$ $1.57, p<.12]$.

\section{GENERAL DISCUSSION}

Our findings on geographical slant perception are consistent with Gibson's (1979) proposal that the perception of surface layout is best described as a perception of affordances. Gibson coined this term to denote the relationship between the physical attributes of things in the world and an organism's potential actions with them. With regard to geographical slant, an important affordance of hills is their walkability, including the ease and effort entailed in traversing surfaces of varying inclinations. Throughout the following discussion, we will summarize our findings on geographical slant perception and relate them to their affordance values.

\section{In Visual Awareness, Geographical Slant Is Overestimated}

For all of the real and virtual hills assessed, geographical pitch was grossly overestimated in verbal and visual measures, which we take to be good indicators of the phe-
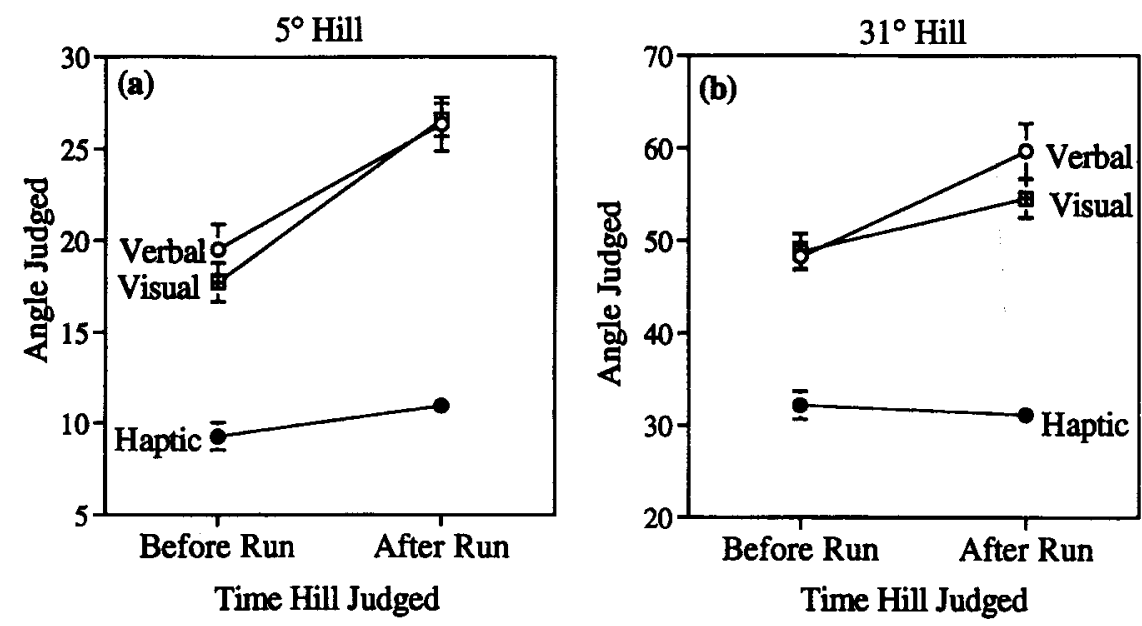

Figure 17. Mean pitch judgments by runners before and after their runs for Experiment 5: (a) $5^{\circ}$ hill; (b) $31^{\circ}$ hill. 
nomenal awareness of pitch. Our own experience, as well as Kammann's (1967) and Ross's (1974) reports, had persuaded us that geographical slant was overestimated, long before we ran the experiments reported herein. To look at a $10^{\circ}$ hill-typically judged to be about $30^{\circ}$ by verbal reports and visual matching-and to be told that it is actually $10^{\circ}$ is an astonishing experience for anyone unfamiliar with the facts of geographical slant overestimation. Many of our subjects were incredulous during their postexperimental briefing. A $10^{\circ}$ hill looks very steep and is quite difficult to ascend for any distance. Again, recall that the legal limit for roads in the state of Virginia is $9^{\circ}$.

Given that most of our walking is restricted to slants of less than $10^{\circ}$, it is more important for people to be sensitive to differences in slants within this range as opposed to larger angles. For example, ascending a $6^{\circ}$ hill requires far more effort than does climbing one of $2^{\circ}$, whereas the difference between $66^{\circ}$ and $62^{\circ}$ inclines has no behavioral significance. As noted by Ross (1974), Murray (1947) reported that rock climbers found it difficult to distinguish between a $77^{\circ}$ rock face and one of $90^{\circ}$.

As is found for intensity judgments of other perceptual dimensions such as brightness or loudness, people's estimates of geographical pitch conform to power functions. For hills viewed from the base, pitch must increase more than three times in order for it to be judged as having doubled. A virtue of such ratio-scaled magnitude estimations is that they allow for higher sensitivity to incremental changes at small values relative to larger ones. We did not assess sensitivity, per se; however, we have no doubt that, if presented with real or simulated hills, people would show a much higher sensitivity to a given increment of angular change at small angles relative to larger ones. After all, many of the informational sources for pitch angle, such as the compression of texture, change at a greater rate at small angles from the horizontal.

That geographical pitch perception conforms to power functions is well suited to the behavioral requirement that people must be able to make finer distinctions between small angles than between large ones. This virtue of slant overestimation does not explain the mechanisms by which perspective information is transformed into judgments that conform to power functions; however, it does capture well the functional utility of these overestimations.

Perceived steepness provides information about the affordances of hills, which include the possibility of traversing them and effort entailed in doing so. A long $10^{\circ}$ hill looks very steep and it presents a daunting challenge if one's intent is to climb it. When one is confronted with a $10^{\circ}$ hill, its apparent steepness informs conscious decisions about how an ascent will be achieved. If walkers are unwilling to become sweaty and out of breath, they must select a gait that will allow them to arrive at the top in the aerobic state that they desire. We believe that an important function of conscious slant perception is to inform the planning and modulation of gait with respect to the hills that are to be traversed so as to expend energy at a desired rate. Slant overestimation serves this purpose by exagger- ating the apparent steepness of hills in a manner that relates inclines to our behavioral potential. Although the planning of molar, long-term aspects of gait is facilitated by perceiving an exaggeration of slant, the local task of visually guiding one's feet is not.

\section{Visually Guided Actions Show Little or No Evidence of the Phenomenal Overestimation of Geographical Slant}

Our haptic measure of pitch showed very little evidence of slant overestimation. The haptic responses did differ significantly from the true values in three of the first four experiments; however, the magnitudes of these differences were quite small when compared with the verbal and visual measures. In addition, the fatigue manipulation that influenced verbal and visual responses in Experiment 5 did not affect haptic adjustments. Finally, Kinsella-Shaw et al. (1992) found a high degree of accuracy when matching a visually presented incline to the pitch of a ramp felt by an unseen foot. Together, we take these findings to indicate that visually guided actions are relatively immune to slant overestimations. To suggest otherwise would imply that people would stumble whenever there was a change in the slant of the terrain over which they walked.

The lack of correspondence between phenomenal reports and visually guided actions is not a new finding; rather, it has been found in a variety of contexts. For example, Bridgeman, Lewis, Heit, and Nagle (1979) found that people could not reliably detect a small target motion that occurred during a saccade; however, when asked to point to its remembered location with their unseen hand, they took the target motion into account. Loomis, Da Silva, Fujita, and Fukusima (1992) found that, although people underestimate the distance in depth between targets, when blindfolded they can walk to each target's location without systematic error and can accurately point to the targets while walking in a lateral direction. Clinical studies have shown that people with visual agnosia resulting from damage to the occipitotemporal region of the brain are often unable to recognize or verbally describe objects in their surroundings, yet they can locomote with little difficulty (Farah, 1990). Goodale and Milner (1992) described a patient with visual agnosia who, when presented with rectangular blocks of different dimensions, could not distinguish between them; however, when asked to pick them up, she accommodated the size of her grasp appropriately for the blocks' sizes.

There are two accounts for why visual awareness of geographical slant exhibits gross overestimations whereas visually guided actions do not. By one account, actions are mediated by visual awareness following a transformation that compensates for overestimations. The other account postulates that conscious awareness and action are informed by separate visual pathways, one showing evidence of bias and the other not. These accounts need not be mutually exclusive, and we believe that evidence supports both.

By the first account, visually guided actions are informed by conscious visual awareness. Foley $(1977,1980)$, for ex- 
ample, has proposed that although verbal and manual indices of perceived distances differ greatly, they are related to a single perceptual variable via distinct output transformations. In the case of perceived slant overestimations, the visual control of actions could compensate for perceived overestimations by calibrating motor programs through feedback: Thus, for example, the motor response to an apparent pitch angle of $30^{\circ}$ would be to raise the foot by an amount consistent with a $10^{\circ}$ distal pitch. Motor programs could be continuously recalibrated to maintain the appropriate mapping between apparent slant and successful actions. Accurate slant perception is unnecessary; rather, as long as perceived slant covaries with distal slant in a lawful monotonic manner, then the apparent overestimations that inform actions will be transparent in performance.

There is good evidence that actions are informed by conscious slant perception in just this manner. This evidence comes from the assessments of internal consistency that were made between the three slant measures. In particular, it was found that the haptic response to a hill of a given incline is the same as the haptic response to a verbally given angle that would be evoked when viewing that incline. For example, when people view a $10^{\circ}$ hill, they say that it appears to be about $30^{\circ}$ but adjust the palm board to just a little over $10^{\circ}$ with their unseen hand. When asked to set the palm board to $30^{\circ}$, they will again set it to an angle that is a little greater than $10^{\circ}$. Thus, their responses to visually presented hills and verbal instructions are the same. This implies that haptic judgments are calibrated to the apparent slant overestimations that inform verbal reports.

By the second account, visual awareness and motoric actions are informed by separate visual pathways. Beginning with a division among retinal ganglion cells, one subdivision terminates in the parvocellular layer of the lateral geniculate nucleus and the other terminates in the magnocellular layer. Termed parvo and magno respectively, these subdivisions remain fairly well segregated and provide the visual inputs for the inferotemporal and posterior parietal cortex respectively. Ungerleider and Mishkin (1982) have identified these ventral (inferotemporal) and dorsal (parietal) regions of the cortex as supporting distinct visual functions. Modifying an earlier proposal by Schneider (1969), they suggested that the ventral system is primarily concerned with object identification, the "what" of perception, whereas the dorsal system supports the mechanisms responsible for spatial localization, the "where" of perception. More recently, the different functions that these separate systems support have come to be described as "what" versus "how," meaning that the ventral system supports a conscious visual awareness of object properties, whereas the dorsal system supports visually guided actions (Goodale $\&$ Milner, 1992). Although these two systems are anatomically distinct, interconnections between them do exist (Ferrera, Nealey, \& Maunsell, 1994; Nealey \& Maunsell, 1994).

With respect to geographical slant, it seems highly plausible that visual awareness and visually guided actions are informed by these separate visual systems. Support for this possibility comes from the differential effect of fatigue on verbal and visual judgments versus haptic ones. In Experiment 5, it was found that, after an exhausting run, hills were reported to be a good deal steeper on the verbal and visual measures; the haptic adjustments, however, were unaffected. This suggests a dissociation between the informational basis for verbal and visual reports and that for motor adjustments. It is, however, possible that visually guided actions were recalibrated throughout the runners' excursions in such a way that the transformation mapping conscious visual experience into haptic adjustments was modified to nullify the increased overestimation of slant. We think that this alternative is less plausible than the separate visual systems account, but we have no evidence against it.

In summary, we propose that the radically different pitch estimates obtained with verbal and visual reports versus haptic adjustments are due both to the dissociation in the visual pathways that inform these two sorts of responses and to the calibration mechanisms that coordinate their functioning. This account is consistent with the mounting evidence for separate "what" and "how" visual systems as well as the evidence indicating that there exist anatomical interactions between these pathways. That pitch overestimations vary with physiological state while actions remain unaffected suggests that these different responses are informed by separate systems. That people set the palm board to $10^{\circ}$ both when looking at a $10^{\circ}$ hill that they verbally estimate to be $30^{\circ}$ and when told to set it to $30^{\circ}$ indicates that the action system does, indeed, compensate for phenomenal slant overestimations.

\section{Geographical Slant Perceptions Reflect People's Behavioral Potential}

The finding that steep hills appear steeper when viewed from the top rather than the bottom is consistent with the notion that perceived steepness relates slant angles to one's action potential. With considerable effort, one could walk up one of the $30^{\circ}$ hills used in our studies; however, they are too steep to walk down. Perceived slant provides useful information about the affordance of traversing a hill. A hill that is too steep to walk on will look steeper than one that is not. Since the walkability of a $30^{\circ}$ hill depends on whether one's intent is to walk up or down it, such a hill looks steeper from the top.

The affordance notion is similarly consistent with the finding that people estimated hills to be steeper on the verbal and visual measures after becoming fatigued. Phenomenal steepness is not invariant with respect to distal inclinations, but rather it preserves the relationship between locomotor effort and slant. Apparent steepness informs people about the effort entailed in traversing hills, and thus, slant overestimation becomes increasingly exaggerated with fatigue. Because of this, people need not assess both the slant of a hill and their own physiological state in order to plan a comfortable ascent; rather, apparent steepness is the only variable that needs to be consulted, since it covaries with both distal slant and physiological state.

The change in perceived pitch that was caused by fatigue is a dramatic demonstration that visual perceptions 
can be influenced by physiological state. This finding is reminiscent of earlier work in which it was attempted to show that visual perceptions were affected by value and need. These prior investigations, however, yielded equivocal results. The best known study in this regard was that of Bruner and Goodman (1947), who reported two findings. First, the size of coins was found to be overestimated in proportion to their worth, meaning that the size of a nickel was overestimated more than a penny, and likewise, the size of a quarter was overestimated more than a nickel. The second finding was that this relationship between apparent size and monetary value was more pronounced for poor children than for rich ones. This study inspired a considerable amount of research and debate related to whether the reported effects were real or artifactual. With regard to the first finding, literature reviews have been written that support the proposed influence of value on size perception (Tajfel, 1957) and that argue against this conclusion (McCurdy, 1956). The obtained relationship between family wealth and the overestimation of coin sizes should be interpreted with considerable caution. Bruner and Rodrigues (1953) noted that, "As a psychological variable, economic status by itself leaves much to be desired" (p. 18). Far too many factors covary with economic status to allow for a definitive conclusion that the different size judgments obtained for the rich and poor groups were due to apparent need.

We believe that the hypothesized relationship between perceived size and value and need is of a different kind than that between perceived slant and physiological state. In the case of the coin perception studies, there is no consequence to overestimating a coin's size in proportion to one's economic status. That is, the proposed relationship between size perception and value and need serves no behavioral function. There is, however, a functional relationship that is supported by the covariance of apparent slant with physiological state. Apparent slant informs a walker about how much effort he/she will have to expend in traversing a hill, and this relationship is preserved over time through fatigue's influence on slant perception. We suspect that the perception of environmental properties is relatively immune to dispositional factors unless these factors directly affect activities that must be accommodated to these properties.

\section{CONCLUSION}

Hills appear steeper than they are. This exaggeration of geographical slant preserves the relationship between distal inclination and our behavioral potential. Steep hills are more difficult to descend than ascend, and accordingly, they appear steeper when viewed from the top. Hills are harder to traverse as people become tired, and consequently, apparent slant increases with fatigue. As is required for successful locomotion, visually guided actions do not reflect apparent slant overestimations, nor are they influenced by fatigue.

We conclude with a final anecdote of the sort that motivated these experiments. In the runners' guide to the 1994

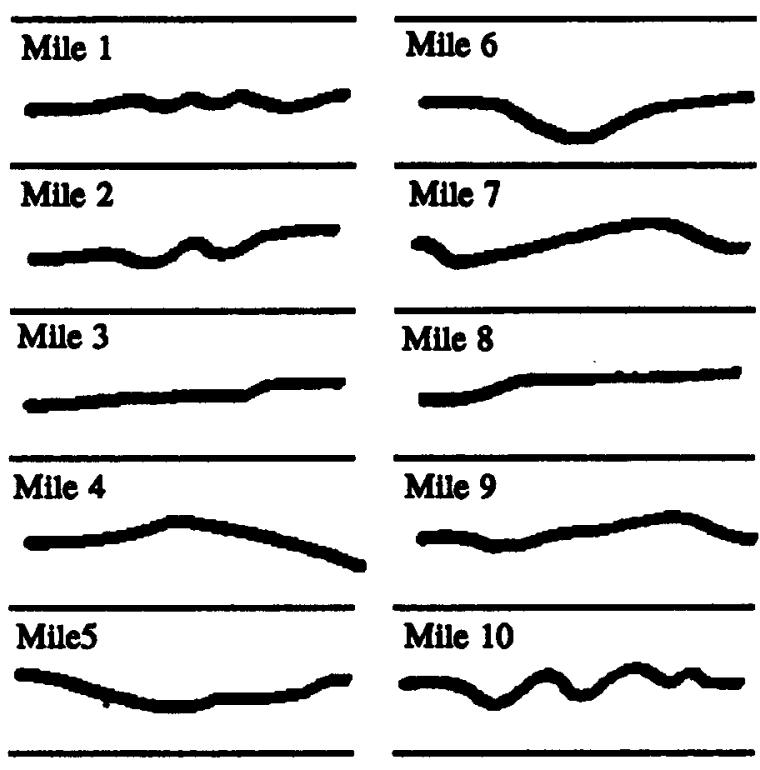

Figure 18. A depiction of the elevation changes for each mile of the "Charlottesville Ten Miler" foot race.

"Charlottesville Ten Miler" foot race, there is a description of the course. A figure is provided with a sketch of the terrain's elevation changes broken down by mile. Beneath each sketch is a written description of that segment of the course. Figure 18 is a copy of the terrain sketches. Once again, the race organizers appear to have arranged for the steepest hills to be located at the end of the race. Notice especially that the last mile is drawn as having much larger hills than does the first. In fact, the first and last miles are identical! Beneath the depiction of the last mile is the following description: "The last mile of the course retraces the rolling first mile. By now the downhills are more painful for some runners than the uphills" (p. 10). We are confident that the different depictions of the first and last miles of the "Charlottesville Ten Miler" accurately show the change in how the same stretch of the race course was perceived by runners early and late in race.

\section{REFERENCES}

Braunstein, M. L. (1968). Motion and texture as sources of slant information. Journal of Experimental Psychology, 78, 247-253.

Bridgeman, B., Lewis, S., Heit, G., \& NaGle, M. (1979). Relationship between cognitive and motor systems of visual position perception. Journal of Experimental Psychology: Human Perception \& Performance, 5, 692-700.

BRUNER, J. S., \& GoOdMAN, C. C. (1947). Value and need as organizing factors in perception. Journal of Abnormal \& Social Psychology, 42, 33-44.

Bruner, J. S., \& Rodrigues, J. S. (1953). Some determinants of apparent size. Journal of Abnormal \& Social Psychology, 48, 17-24.

Clark, W. C., Smith, A. H., \& Rabe, A. (1956a). The interaction of surface texture, outline gradient, and ground in the perception of slant. Canadian Journal of Psychology, 10, 1-8.

Clark, W. C., Smith, A. H., \& Rabe, A. (1956b). Retinal gradients of outline distortion and binocular disparity as stimuli for slant. Canadian Journal of Psychology, 10, 77-81.

EPSTEIN, W. (1981). The relationship between texture gradient and perceived slant-in-depth: Direct or mediated? Perception, 10, 695-702. EPSTEIN, W., \& MounTford, D. (1963). Judgments of slant in response 
to an isolated gradient of stimulation. Perceptual \& Motor Skills, 16, 733-737.

EPSTEIN, W., \& PARK, J. N. (1963). Shape constancy: Functional relationships and theoretical formulations. Psychological Bulletin, 60, 265-288.

ERIKSSON, E. S. (1964). Monocular slant perception and the texture gradient concept. Scandinavian Journal of Psychology, 5, 123-128.

Farah, M. (1990). Visual agnosia. Cambridge, MA: MIT Press.

Ferrera, V. P., Nealey, T. A., \& Maunsell, J. H. R. (1994). Responses in macaque visual area $\mathrm{V} 4$ following inactivation of the parvocellular and magnocellular LGN pathways. Journal of Neuroscience, 14, 2080-2088.

FLOCK, H. R. (1964). Some conditions sufficient for accurate monocular perceptions of moving surface slants. Journal of Experimental Psychology, 67, 560-572.

Flock, H. R., Graves, D., Tennet, J., \& Stepehenson, B. (1967). Slant judgments of single rectangles at a slant. Psychonomic Science, 7, 57-58.

FoLEY, J. M. (1977). Effect of distance information and range on two indices of visually perceived distance. Perception, 7, 449-460.

Foley, J. M. (1980). Binocular distance perception. Psychological Review, 87, 411-434.

Freeman, R. B. (1966a). Absolute threshold for visual slant: The effect of stimulus size and retinal perspective. Journal of Experimental Psychology, 71, 170-176.

FreEMAN, R. B. (1966b). The effect of size on visual slant. Journal of Experimental Psychology, 71, 96-103.

Gibson, J. J. (1950). The perception of visual surfaces. American Journal of Psychology, 63, 367-384.

GiBson, J. J. (1979). The ecological approach to visual perception. Boston: Houghton Mifflin.

GiBson, J. J., \& CORNSWEET, J. (1952). The perceived slant of visual surfaces - optical and geographical. Journal of Experimental Psychology, 44, 11-15.

GrLLAM, B. (1970). Judgments of slant on the basis of foreshortening. Scandinavian Journal of Psychology, 11, 31-34.

Goodale, M. A., \& MilNeR, A. D. (1992). Separate visual pathways for perception and action. Trends in Neurosciences, 15, 20-25.

KAMMANN, R. (1967). The overestimation of vertical distance and slope and its role in the moon illusion. Perception \& Psychophysics, 2, 585-589.

Kinsella-Shaw, J. M., Shaw, B., \& Turvey, M. T. (1992). Perceiving walk-on-able slopes. Ecological Psychology, 4, 223-239.

Kraft, A. L., \& WinNick, W. A. (1967). The effect of pattern and texture gradient on slant and shape judgments. Perception \& Psychophysics, 2, 141-147.

LI, W., \& Matin, L. (1993, November). Prism-generated and real pitch influence egocentric localization similarly; prism generated and real slant don't. Poster presented at the meeting of the Psychonomic Society, Washington, DC.

Loomis, J. M., Da Silva, J., Fujita, N., \& Fukusima, S. S. (1992). Visual space perception and visually directed action. Journal of Experimental Psychology: Human Perception \& Performance, 18, 906-921.

Matin, L., \& Fox, C. R. (1989). Visually perceived eye level and perceived elevation of objects: Linearly additive influences from visual field pitch and from gravity. Vision Research, 29, 315-324.

Matin, L., \& Li, W. (1992). Visually perceived eye level: Changes in- duced by a pitched-from-vertical 2-line visual field. Journal of Experimental Psychology: Human Perception \& Performance, 18, 257-289.

MCCuRDY, H. G. (1956). Coin perception and the concept of schemata. Psychological Review, 63, 160-168.

MurRaY, W. H. (1947). Mountaineering in Scotland. London: Dent.

NeALeY, T. A., \& MAunsell, J. H. R. (1994). Magnocellular and parvocellular contributions to the responses of neurons in macaque striate cortex. Journal of Neuroscience, 14, 2069-2079.

Perrone, J. A., \& Wenderoth, P. M. (1991). Visual slant underestimation. In S. R. Ellis (Ed.), Pictorial communication in virtual and real environments (pp. 496-503). London: Taylor \& Francis.

Phillips, R. J. (1970). Stationary visual texture and the estimation of slant angle. Journal of Experimental Psychology, 22, 389-397.

RoBinett, W., \& Rolland, J. (1991). A computational model for the stereoscopic optics of a head-mounted display. SPIE Proceedings: Stereoscopic displays and applications II, 1457, 140.

Ross, H. E. (1974). Behavior and perception in strange environments. London: George Allen \& Unwin.

SchneJder, G. E. (1969, February 28). Two visual systems. Science, $163,895-902$.

Sмiтh, A. H. (1966). Phenomenal slant as a function of ambiguity of contour perspective. Perceptual \& Motor Skills, 23, 587-594.

Sмiтh, A. H. (1967). Perceived slant as a function of stimulus contour and vertical dimension. Perceptual \& Motor Skills, 24, 167-173.

STOPER, A. E., \& COHEN, M. M. (1989). Effect of structured environments on apparent eye level. Perception \& Psychophysics, 46, 469-475.

Stoper, A. E., Fries, C., \& Bautista, A. (1992, November). The effect of environmental pitch on apparent slant. Paper presented at the meeting of the Psychonomic Society, St. Louis.

TAJFEL, H. (1957). Value and the perceptual judgment of magnitude. Psychological Review, 64, 192-204.

UNGERLEIDER, L. G., \& MishKIN, M. (1982). Two cortical visual systems. In D. J. Ingle, M. A. Goodale, \& R. J. W. Mansfield (Eds.), Analysis of visual behavior (pp. 549-586). Cambridge, MA: MIT Press.

WILLEY, R., \& GYR, J. W. (1969). Motion parallax and projective similarity as factors in slant perception. Journal of Experimental Psychology, 79, 525-532.

\section{NOTE}

1. Research on geographical pitch perception has focused primarily on its influence on variables such as visually perceived eye level (VPEL), which is one of the cues used as a reference in perceiving the height of objects in the visual field. Since body-referenced information plays an important role in the mechanisms controlling the perception of elevation, a change in pitch of the visual field may have important consequences for the localization of an object in the environment. It has been found that VPEL varies linearly with pitch of the visual field (Li \& Matin, 1993; Matin \& Li, 1992; Stoper \& Cohen, 1989). The pitch of a room has also been found to influence other variables such as the perceived elevation and size of objects viewed against the field (Matin \& Fox, 1989) and the apparent slant of a rod (Stoper, Fries, \& Bautista, 1992).

(Manuscript received February 21, 1995; revision accepted for publication April 25, 1995.) 